\title{
State of Technology of Direct Contact Heat Exchanging
}

\author{
R. W. Vallario \\ D. E. DeBellis
}

May 1984

Prepared for the U.S. Department of Energy under Contract DE-AC06-76RLO 1830

Pacific Northwest Laboratory Operated for the U.S. Department of Energy by Battelle Memorial Institute 


\section{DISCLAIMER}

This report was prepared as an account of work sponsored by an agency of the United States Government. Neither the United States Government nor any agency thereof, nor any of their employees, makes any warranty, express or implied, or assumes any legal liability or responsibility for the accuracy, completeness, or usefulness of any information, apparatus, product, or process disclosed, or represents that its use would not infringe privately owned rights. Reference herein to any specific commercial product, process, or service by trade name, trademark, manufacturer, or otherwise, does not necessarily constitute or imply its endorsement, recommendation, or favoring by the United States Government or any agency thereof. The views and opinions of authors expressed herein do not necessarily state or reflect those of the United States Government or any agency thereof.

\section{PACIFIC NORTHWEST LABORATORY operated by \\ BATTELLE \\ for the \\ UNITED STATES DEPARTMENT OF ENERGY under Contract DE-AC06-76RLO 1830}

\begin{tabular}{|c|c|}
\hline \multicolumn{2}{|c|}{ Printed in the United States of America } \\
\hline \multirow{2}{*}{\multicolumn{2}{|c|}{$\begin{array}{c}\text { Available from } \\
\text { National Technical Information Service }\end{array}$}} \\
\hline & \\
\hline \multicolumn{2}{|c|}{$\begin{array}{l}\text { National Technical Information Service } \\
\text { United States Department of Commerce }\end{array}$} \\
\hline \multicolumn{2}{|c|}{5285 Port Royal Road } \\
\hline \multicolumn{2}{|c|}{ Springfield, Virginia 22161} \\
\hline \multirow{2}{*}{\multicolumn{2}{|c|}{$\begin{array}{l}\text { NTIS Price Codes } \\
\text { Microfiche } A 01\end{array}$}} \\
\hline & \\
\hline \multicolumn{2}{|c|}{ Printed Copy } \\
\hline & Price \\
\hline Pages & Codes \\
\hline $001-025$ & A02 \\
\hline 026-050 & $\mathrm{A} 03$ \\
\hline $051-075$ & AO4 \\
\hline $076-100$ & A05 \\
\hline $101-125$ & A06 \\
\hline $126-150$ & $A 07$ \\
\hline $151-175$ & $A 08$ \\
\hline $176-200$ & $A 09$ \\
\hline $201-225$ & $A 010$ \\
\hline $226-250$ & A011 \\
\hline $251-275$ & $A 012$ \\
\hline $276-300$ & $A 013$ \\
\hline
\end{tabular}


$P N L-5008$

UC -95

STATE OF TECHNOLOGY OF DIRECT

CONTACT HEAT EXCHANGING

R. W. Vallario

D. E. DeBell is

May 1984

Prepared for

Energy Conversion and Utilization

Technologies Division

Office of Energy Systems Research

Conservation and Renewable Energy

U.S. Department of Energy

under Contract DE-ACO6-76RL0 1830

Pacific Northwest Laboratory

Richland, Washington 99352 


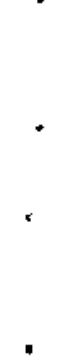


PREFACE

This study was completed for the Division of Energy Conversion and Utilization Technologies (ECUT) in the Department of Energy. The division's mission is to identify and research long-range technology concepts that are attractive for more efficient energy use. To meet its goals, the ECUT staff established a planning and systems analysis project that was responsible for conducting this study.

This report is one of a series of studies in support of the ECUT research planning effort. Other documents in the series contain assessments of energy conservation technology areas, methods to appraise research projects for support, and data reference sources. Publications from this project include the following:

Abarcar, R., and D. Johnson. 1983. ECUT Data Reference Series: Lightweight Materials for Ground Transportation. Pacific Northwest Laboratory, Richland, Washington.

Abarcar, R., and D. Johnson. 1983. ECUT Data Reference Series: Materials for Advanced Heat Engines. Pacific Northwest Laboratory, Richland, Washington.

Bomelburg, H. J. 1983. Efficiency Evaluation of Oxygen Enrichment in Energy Conversion Processes. PNL-4917, Pacific Northwest Laboratory, RichTand, Washington.

Chockie, A., et al. 1983. An Evaluation of Stationary Combustion Research Needs. Pacific Northwest Laboratory, Richland, Washington.

Chockie, A., and D. Johnson. 1983. ECUT Data Reference Series: Stationary Combustion Systems. Pacific Northwest Laboratory, Richland, Washington.

Hane, G. 1983. Efficiency Evaluation of the DISC, DHC, and DI Diesel Engines. PNL-4568, Pacific Northwest Laboratory, Richland, Washington.

Hane, G., et al. 1983. A Preliminary Overview of Innovative Industrial Materials Processes. PNL-4505, Pacific Northwest Laboratory, Richland, Washington.

Hane, G., et al. 1984. A Review of Studies of Research Opportunities in Energy Conservation. PNL 4571, Pacific Northwest Laboratories, Richland, Washington. 
Hane, G. and D. Johnson. 1983. ECUT Data Reference Series: Otto Cycle Engines in Transportation. Pacific Northwest Laboratory, Richland, Washington.

Hopp, W., et at. 1981. An Overview of Energy Conservation Research Opportunities--Executive Summary. PNL-3944 Ex. Sum., Pacific Northwest Laboratory, Richland, Washington.

Hopp, W., et al. 1981. An Overview of Energy Conservation Research Opportunities. PNL-3944, Pacific Northwest Laboratory, Richland, Washington.

Hopp, W., et a1. 1982. Identification of Energy Conservation Research Opportunities: A Review and Synthesis of the Literature. PNL-3966, Pacific Northwest Laboratory, Richland, Washington.

U.S. Department of Energy, 1981. The 1981 ECUT Work Element Appraisal. DOE/CE-0024, U.S. Department of Energy, Washington, D.C.

U.S. Department of Energy. 1983. Energy Conversion and Utilization Technologies Program Report, 1981-1982. U.S. Department of Energy, Washington, D.C.

Young, J., and D. Johnson. 1983. ECUT Data Reference Series: Ammonia Synthesis. Pacific Northwest Laboratory, Richland, Washington.

0. L. Brenchley

Project Manager 


\section{ACKNOWLEDGMENTS}

The authors would like to extend their appreciation to the ECUT Program and to Marvin Gunn, the technical monitor of this project. The authors would also like to thank D. L. Brenchley, G. J. Hane, and R. A. Hutchinson of Pacific Northwest Laboratory for their insight and technical review. Finally, the authors would like to express their appreciation to R. J. Goldstick, the various other information sources too numerous to mention individually, other reviewers of the draft report, and J. E. Danko for her editing contributions. 


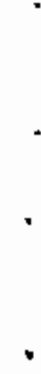

$x$

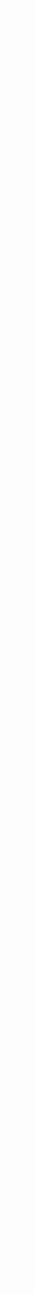




\section{CONTENTS}

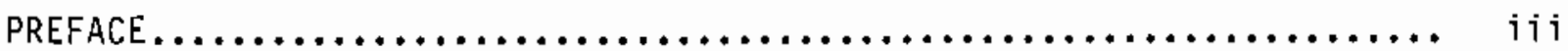

ACKNOWLEDGMENTS ..................................

1.0 SUMMARY AND CONCLUSIONS............................ 1.1

2.0 INTRODUCTION...................................... 2.1

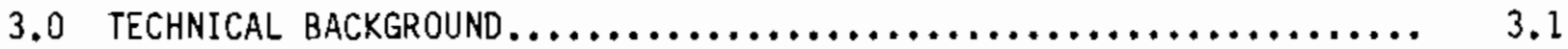

4.0 STATE OF TEChNOLOGY ASSESSMENT........................ 4.1

4.1 LIQUID/LIQUID................................. 4.1

4.1 .1 Industrial Waste Heat Recovery................. 4.1

4.1 .2 Geothermal.............................. 4.2

4.1 .3 Solar.................................... 4.8

4.1 .4 other.................................. 4.9

4.2 LIQUID/SOLID.................................. 4.10

4.2.1 Thermal Storage.......................... 4.11

4.3 LIQUID $/$ GAS.................................. 4.13

4.3 .1 Other.................................. 4.13

4.4 GAS/LIQUID................................... 4.16

4.4 .1 Industrial Waste Heat Recovery................. 4.16

4.4 .2 Therma Storage......................... 4.21

4.4 .3 Solar..................................... 4.21

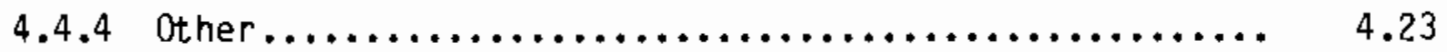

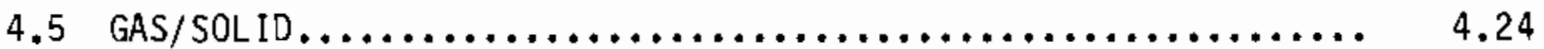

4.5 .1 Industrial waste Heat Recovery................. 4.24

4.5 .2 Thermat Storage.......................... 4.27

5.0 STATE OF TECHNOLOGY ASSESSMENT - FOREIGN PERSPECTIVE.......... 5.1 
6.0 RESEARCH AND DEVELOPMENT NEEdS $\ldots \ldots \ldots \ldots \ldots \ldots \ldots \ldots \ldots \ldots \ldots \ldots \ldots, 6.1$

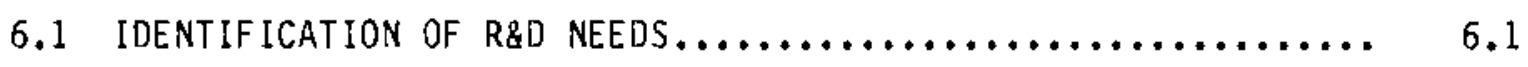

6.1 .1 Generic R\&D............................... 6.1

6.1 .2 Phase-Combination-Oriented R\&D.................. 6.3

6.1 .3 Application-Oriented R\&D................... 6.5

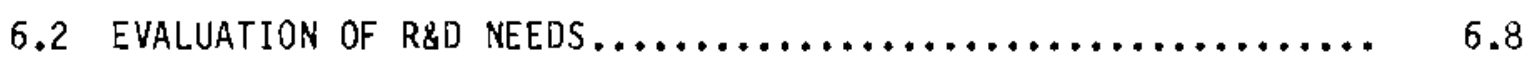

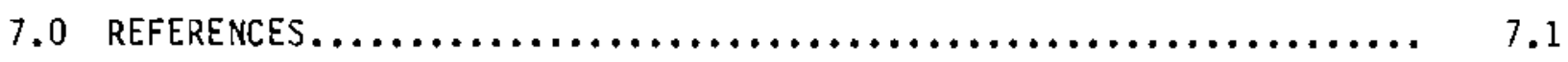




\section{FIGURES}

3.1 Several Basic Types of DCHE Vessel Configurations............. 3.3

3.2 Internal Components in Tower Design....................... 3.5

\section{TABLES}

5.1 List of Manufacturers Surveyed by GRI $\ldots \ldots \ldots \ldots \ldots \ldots \ldots \ldots \ldots, 5.3$

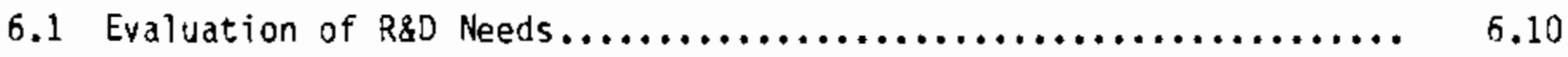




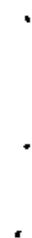




\subsection{SUMMARY AND CONCLUSIONS}

A direct contact heat exchanger (DCHE) transfers heat between two relatively immiscible media streams that are in direct physical contact with one another. Because there is no barrier or wall separating the media, the net effect is to increase heat transfer efficiency over that obtainable through use of conventional heat transfer equipment.

Direct contact heat exchange systems can save energy, costs, and space. For instance, the energy savings from just one application of direct contact technology--condensation waste heat recovery--has been estimated to be as high as 0.3 quads ( $10^{15} \mathrm{Btu}$ ) if only those systems with payback periods less than two years were installed. Over 0.5 quads could be saved if all such applications were considered (Goldstick 1981).

Despite the promise of DCHE systems, however, they have not been fully developed or widely adopted in the U.S. In view of the potentially large energy savings that is possible with DCHE technology, Pacific Northwest Laboratory was requested by the Department of Energy, under the auspices of the Energy Conversion and Utilization Technologies (ECUT) Program, to examine those barriers that are limiting the application of this technology in the U.S.

Specific objectives of this study were to assess the state of technology development and to identify and evaluate the constraints to wider use of DCHE technology in the U.S. The scope of this study is relatively broad; it includes many types of generic systems and end-use applications, both current and future. Domestic and foreign experience with DCHE technology are compared, although the primary focus is on domestic experience.

Twenty-two distinct applications of DCHE technology were identified in this study and are examined in this report. The general format is to describe each system, explore its potential applications, discuss current and past research activities and identify major implementation barriers. Finally, as a result of discussions with principal users of DCHE systems and with other knowledgeable sources, generic and specific R\&D needs to overcome specific 
implementation barriers have been identified. The following list of DCHE systems/concepts has been classified into four major end-uses; there is also a category for specialized (other) applications.

INDUSTR IAL WASTE HEAT RECOVERY

1. 0 il/freon power generation system

2. condensation water heating

3. two-stage condensation media heating

4. biphase turbine power generation

5. "raining packed bed" gas/solid system

6. "falling cloud" gas/solid system

7. vibro-fluidized" gas/solid system

8. molten salts and glassy slag high-temperature systems.

GEOTHERMAL

1. brine contacting organic working fluid in Rankine cycle.

THERMAL STORAGE

1. form-stable polyethylene rods

2. "heat battery" using salt hydrates in oil

3. salt/freon systems

4. pumpable salt slurry with crystal habit modifiers

5. porous sintered ceramic structure incorporating liquid thermal salts.

SOLAR

1. salt-gradient solar pond with pentane working fluid

2. solar heating of water using diethyl phthalate (DEP)

3. solar central receiver coupled with glassy slag thermal storage.

OTHER (SPECIALIZED) APPLICATIONS

1. desalination using freezing or boiling methods

2. submerged combustion heating of liquids 
3. vortex-flow direct contact combustion water heating

4. "bubble-up" gas-dispersed direct contact liquid heating

5. liquid metal droplet DCHEs for thermal management in space.

The following general observations summarize $\mathrm{PNL}$ findings with regard to the state of technology development of direct contact heat exchangers in the U.S.:

- Direct contact heat exchanging is a valuable, emerging technology "in search of a good home" (i.e., some good specific applications). Many industry design and processing engineers are unaware of either the potential benefits of DCHEs in general, or more importantly, of any commercially available designs.

- The majority of DCHE designs/ideas are conceptual or experimental at this time.

- The majority of R\&D activity and private sector interest involves those applications intended for industrial waste heat recovery and thermal storage. Cutbacks in federal funding for geothermal and solar systems have slowed progress in these areas.

- European experience in DCHE has greater depth in some areas but less breadth than that of U.S. research counterparts.

Direct contact condensation waste heat recovery is probably the most important single application of the technology (see Section 4.4.1 for process description). Ironically, the technology has not been widely used in the United States for reasons not wholity related to technical problems or technical R\&D needs. Rather, the main problem appears to be one of credibility. Many potential users are not adequately informed about the technology. In addition, many industry representatives seem to belong to the "it sounds too good to be true" school of thinking. The unfortunate part is that these same plant managers or engineers need only examine the operating experience of European counterparts to confirm the validity of manufacturer's and developer's claims. For in Europe, such systems have been used with great success for over ten years. Recent estimates indicate that over 3000 units are installed and working there. By comparison, only 200 units have been installed in the U.S. 
and the majority of these installations have been made only as recently as the last couple of years. At the risk of being repetitious, the fundamental barrier to widespread use of condensation waste heat recovery systems here in the U.S. is that many potential users are locked into traditional modes of thinking. Expanded efforts to educate potential users to the advantages of this technology in various applications are definitely needed to accelerate the commercial acceptance and use of this technology in the U.S.

In addition to direct contact condensation waste heat recovery, several other highly promising technologies and/or systems that utilize direct contact heat transfer principles were identified. It was not possible to prioritize the importance of the commercial development of these technologies/applications because there is no common denominator for drawing such comparisons--they impact different potential end-use applications. However, the authors feel that all these technologies/application have significant potential for effecting large energy savings and further development could result in important technological advancements. Thus, these highly promising technologies are distinguished from the multitude of technologies discussed in the main body of this report. These technologies/applications are as follows: 1) high-temperature industrial waste heat recovery (e.g., molten salt concepts) for applications to dirty and corrosive waste gas streams, 2) use of organic working fluid cycles that could produce electricity by tapping into moderate temperature (i.e., up to $500^{\circ} \mathrm{F}$ ) waste gas streams, 3) development of low-temperature heat engines that could produce useful electricity onsite using large quantities of low-temperature heat captured by such systems as direct contact condensation waste heat recovery, and 4) development and refinement of suitable thermal storage designs that can be used in a range of applications from central solar receivers to residential home heating and cooling.

One of the objectives of this study was to identify principal barriers to the commercial development and large-scale usage of promising direct contact technology applications. These barriers along with corresponding R\&D needs, are identified below for each of these individual technology applications. 


\section{Technology}

1. Direct contact condensation waste heat recovery

2. High-temperature direct contact waste heat recovery

3. Direct contact organic working fluid cycles

4. Low-temperature heat engines
Barrier(s) to Commercial Implementation

- Limited understanding and acceptance by potential users
R\&D Needs

- Enhance technology transfer

- Perform systems analyses of low-temperature heat needs and utilization

- Lack knowledge of media response and characteristics

- Not fully demonstrated

- Unable to identify working fluid(s), with necessary operating characteristics and suitable designs have not been identified or fully developed

- Re1iable, inexpensive designs have not been fully developed

- Media selection, testing, and response characteristics are not fully understood

- Cost effective, reliable designs have not been fully developed.
- Identify and test suitable media and designs under varying conditions

- Identify and test various designs and medias

- Examine working fluid degradation and carryover responses

- Design and develop low-temperature heat engines - refine old ideas, develop new ones

- Improve understanding of media behavior in different applicaions and factor into designs

- Incorporate into designs the need for low-cost corrosionresistant materials, where appropriate

To summarize, direct contact heat transfer technology holds considerable promise for many areas of application within the United States. Of all the application areas, industrial manufacturing and processing is one of the greatest potential beneficiaries of such technology. However, further work is needed to determine those specific areas within the manufacturing and processing industries that could benefit from DCHE technology in its many forms. 
Accordingly, we strongly recommend a study to determine specific areas where direct contact heat exchangers can be applied in the manufacturing and processing industries (i.e. according to major industry category by SIC code). A data base that models industrial processes and characterizes process and waste heat streams in manufacturing and processing industries was recently developed under funding provided by the DOE's office of Industrial Programs. (a) This data base provides a powerful analytic tool for determining where DCHEs could be used to improve energy efficiency and use in specific industrial applications.

(a) Wilfert, G. L. et a1. 1983. Characterization of Industrial Process Waste Heat and Input Heat Streams. PNL 4912, Pacific Northwest Laboratory, Richland, washington 99352 . 


\subsection{INTRODUCTION}

The objective of this study is to present an overview of the state of development of direct contact heat exchange technology. This overview includes consideration of the various types of direct contact devices, their actual and potential applications, the present state of research, principal barriers to implementation, and research and development needs to overcome these implementation barriers. Both domestic and foreign experience with direct contact heat exchange technology are reviewed.

For the purposes of this study, the direct contact heat exchanger (DCHE) is defined as a device that transfers heat between two distinct immiscible media streams that are in direct physical contact with one another. In formulating this study definition, the intention is to be as flexible as possible in selecting systems for consideration, while limiting to manageable proportions, the vast number of systems which could be called direct contact. None of the systems reviewed can be considered perfect direct contact devices. Some degree of miscibility and chemical interaction always exists between media streams. Consequentiy, heat transfer never takes place solely by the processes of conduction, convection, and radiation. The basic question that needs to be addressed (but that is hard to answer categorically) is how removed can a system become from the definition of an ideal direct contact heat exchanger before it is no longer considered a direct contact system? The study definition should be viewed as a broad guideline for system consideration and not as a rigid classification criterion. Processes in which significant chemical interaction takes place between the media streams and heat transfer occurs primarily through the processes of conduction, convection, or radiation rather than by mass transfer are not considered. Many petrochemical processes where direct contact heat transfer occurs but in conjunction with mass transfer and chemical reaction between media are also eliminated. Drying processes, wet cooling devices, and conventional direct contact condensers are not considered. An additional criterion for consideration is the degree of innovation exhibited by the concept. Thus, well-established technologies that could be classified as direct contact heat exchangers by the study definition, such as regenerators and rotary kilns, are not examined. 
For purposes of assessing the state of technology development, DCHES are classified by the phases of the media involved. This classification scheme provides a convenient reference point because technical problems tend to be grouped somewhat more strongly around the type of DCHE than the application area. Since phase change of one or both media can occur in some concepts, the phase of the medium as it enters the OCHE is used. For example, a geothermal design in which a low boiling point hydrocarbon is vaporized by geothermal brine is classified as a liquid/liquid DCHE because both media streams enter as liquids. In direct contact thermal energy storage devices, the phase of the medium before thermal charging is used for classification purposes. A unit that stores energy by melting a salt with hot liquid is considered to be a solid/liquid direct contact device. A finer distinction must be made for gas/liquid systems because the dispersed phase can be either the gas or the liquid. For purposes of this study, systems with the gas dispersed will be termed "liquid/gas" DCHEs, while systems with the Tiquid dispersed will be termed "gas/liquid" DCHEs.

The reader can find adequate description (with appropriate diagrams) of the generic DCHE designs in many references in the open 1iterature. Because design description is widespread in the literature, it is not repeated in any great detail in this study. However, it is important to realize that within the categories we have established for this study (i.e., based on phase of the involved media) there are additional design features, beyond the basic vessel configuration, that can produce a multitude of desired effects and mitigate a variety of problems. Specificaliy, these design features often involve internal components ("internals") whose main purpose is to prevent backmixing and to increase heat transfer characteristics. Examples of several of these internal design features and the basic vessel configurations are presented in Chapter 3.0. Because they are not necessarily dependent on phase combination and can often be applied to a variety of fluid combinations, these design features are treated, for the most part, implicitly in the majority of the text that follows Chapter 3.0 .

The research and development needs identified in this study were determined from a variety of sources. Data collection methods are discussed in 
Chapter 6.0. Research and development needs are classified on three different levels (in descending order of generality): generic research, phase combination oriented research and application oriented research. These categories correspond to three perceived levels of technological problems (barriers). Generic $R \& D$ needs include those research activities identified as having relevance to and potential impact on all manner of technology users and designs. Phase combination oriented $R \& D$ addresses those problems inherent in the design and operation of equipment that employs particular combinations of media. For instance, liquid/liquid DCHEs offer a completely different and unique set of problems compared to solid/liquid direct contact heat exchangers. And finally, application oriented R\&D needs deal with issues specific to an application category or specific type of end-use activity. For example, because of the specific operating conditions typically found in geothermal systems, it is possible to identify several unique R\&D needs characteristic of DCHEs intended for geothermal applications.

Finally, R\&D needs identified in this report are suhjectively evaluated. The evaluation includes both an assessment of the priority (high or 10w) and the time dependence (i.e., short or long term) of the research. Again, it must be stressed that these evaluations are subjective, although they do reflect extensive industry input and review. There is no attempt in this study to prioritize the identified R\&D needs based on the relative merits of the end-use applications. Such comparison and prioritization is beyond the scope of this study. 


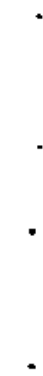




\subsection{TECHNICAL BACKGROUND}

In its conventional form, a heat exchanger is a device that transfers heat from one medium to another through an intervening wall physically separating the media. The majority of heat exchanger designs fall into this category. While conventiona? heat exchangers are well suited to most applications, the presence of a separating wall is a disadvantage in certain situations. Continuous and effective operation in a dirty and/or corrosive environment is often difficult because fouling or corrosion can degrade heat transfer surfaces. Use of conventional heat exchangers in very high temperature situations is constrained because tradeoffs are required between the structural and heat transfer properties of materials. Low-temperature performance (small temperature differences between the media) is hindered by the thermal resistance of the wall and by limitations on achievable and practica? heat transfer areas.

In conventional heat exchangers, fouling problems can be mitigated by various physical and chemical cleaning techniques. However, these techniques may entail significant unit downtime and can be expensive. Operation in corrosive environments can be improved by selecting suitable corrosion-resistant alloys. Similarly, operation at elevated temperatures can be achieved using special high-temperature materials. Again, however, the additional expense may be prohibitive. Acceptable performance in regimes with low temperature difference requires large heat transfer areas to exchange useful amounts of heat.

This requires large exchangers, which results in high material costs.

As its name suggests, a direct contact heat exchanger accomplishes heat transfer between two distinct media brought into direct contact with each other. Both fluid/fluid and solid/fluid systems are possible. One or both of the media can also change phase. The primary requirement is that the two media have a low degree of miscibility with one another, so their separation is relatively easy.

The direct contact heat exchanger (DCHE) has the potential 1) to largely eliminate fouling and corrosion problems, 2) to enable heat exchange at very high temperatures, and 3) to markedly improve performance in low-temperature 
regimes. For these reasons, the DCHE has found actual and potential application in areas where conventional heat exchangers are not practical.

The absence of a separating wall significantly reduces fouling and corrosion concerns. Material savings over an equivalent conventional exchanger are also realized. The absence of a material wall also reduces limitations on high temperature heat exchange. Improved low-temperature performance comes from the ability to achieve large heat transfer areas by finely dispersing one medium in the other. In addition, the heat transfer resistance between the two media is much less because there is no intervening wall. For many applications, these characteristics enable a direct contact heat exchanger to be smaller than an equivalent duty conventional heat exchanger.

There are essentially three generic vessel configurations that could be used in direct contact heat exchanging. These basic vessel configurations are: the tower design, the co-current pipeline design, and the centrifuge design. Diagrams of the basic configurations of these three DCHE vessels are provided in Figure 3.1. The tower design permits gravity separation within the vessel and media streams are generally countercurrent. The tower design is by far the most common DCHE design. The co-current design accomplishes heat transfer through mixing and co-current flow of media streams. The co-current pipeline is not widely seen in practice because of thermodynamic limitations posed by co-current heat transfer. Separation is generally accomplished in another vessel connected in series to the co-current pipeline. Finally, the centrifuge design could be loosely described as a several-stage, back-mix design, whereby separation is enhanced by accelerating the media streams in typical centrifuge fashion. While centrifugal devices have often been used as chemical reactors and separators, whether they could be applied to heat transfer problems and, specifically to direct contact heat transfer has yet to be determined. (a) Nevertheless, it has been suggested as one possible configuration/approach and has been included here as a point of possible research interest.

(a) Discussion with Robert J. Goldstick, Energy Design Services, 0jai, California, December 6, 1983. 
Countercurrent Tower

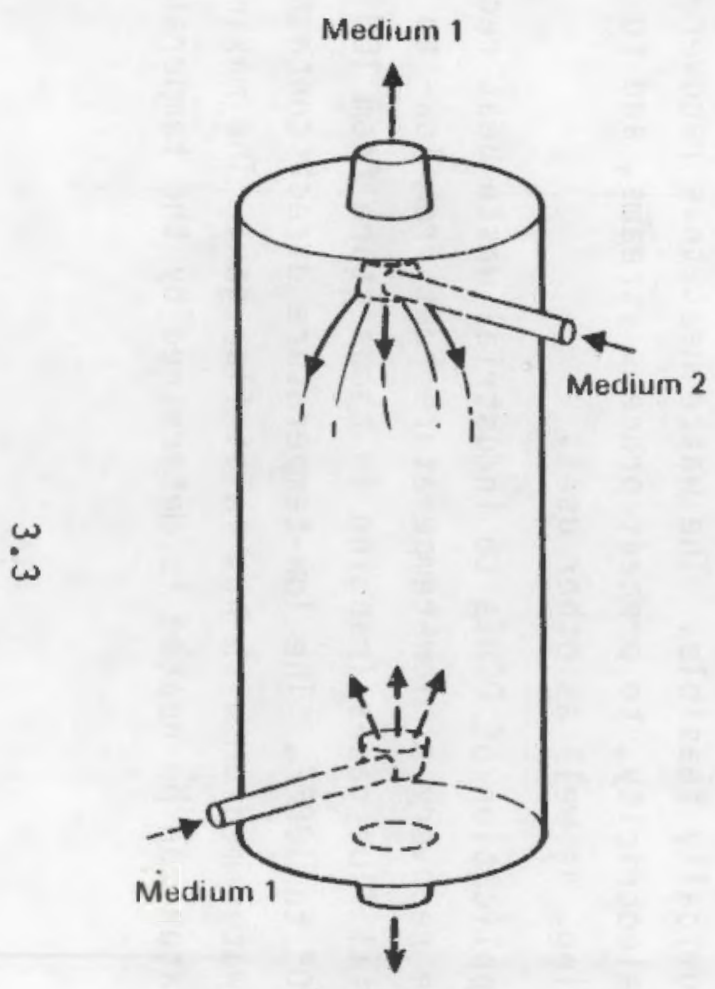

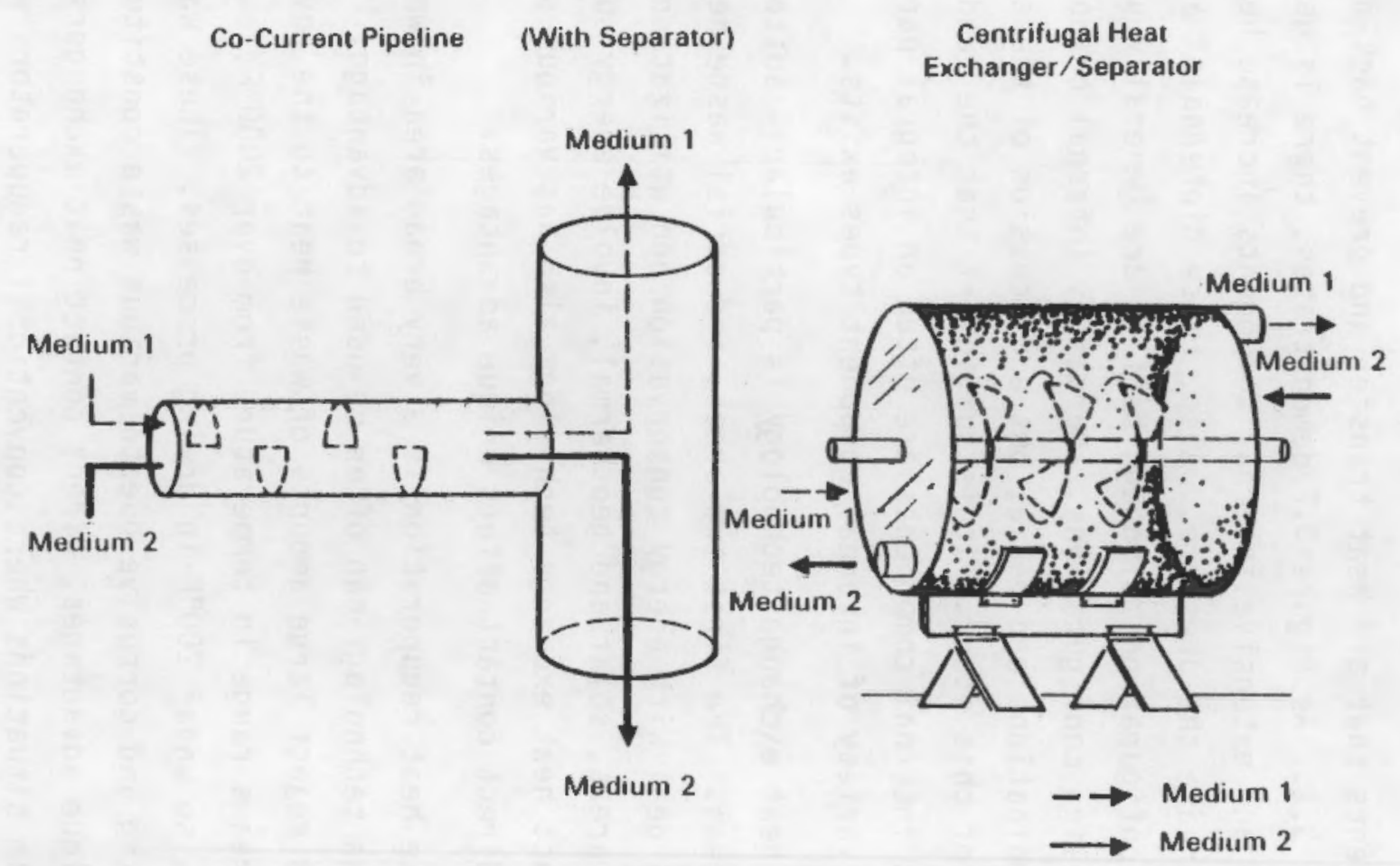

Medium 2

FIGURE 3.1. Several Basic Types of DCHE Vessel Configurations 
Internal components that aid heat transfer and prevent back-mixing are identified in Figure 3.2. As Figure 3.2 demonstrates, there is generally a tradeoff: elaborate and extensive internal components increase heat transfer coefficients but decrease the pressure. Also, these "internals" are most often found in the tower configuration, although baffles are generally used in the other two generic design configurations. Certainly internal components are limited by phase combinations and media, but a discussion of these limitations is beyond the scope of this study. It is sufficient that the reader be made aware that different internal components are often an integral part of DCHE designs, and that a variety of internal component types exists.

Direct contact heat exchange technology is particularly suited to four broad application areas. The first two areas, industrial waste heat recovery and thermal storage, deal with energy conservation and utilization technologies; the last two areas, solar and geothermal, involve energy supply technologies. Direct contact heat exchange technology also has various specific applications where direct contact offers unique advantages.

Industrial waste heat recuperation is a very broad area in which direct contact heat exchange technology can often be used to advantage. Many energy intensive industries reject large amounts of waste heat to the environment. These waste heat streams range in temperature from over $2000^{\circ} \mathrm{F}$, e.g., metal smelting operations, to under $200^{\circ} \mathrm{F}$ in drying processes. These waste streams are also often fouling and corrosive due to various waste constituents. Because of their unique advantages, direct contact heat exchangers could provide heat recovery in situations where conventional recuperators would not be technically or economically feasible. The waste heat thus recovered can be used to cogenerate electricity, to preheat process streams, and to provide space or water heating, as well as other uses.

The one main application of DCHEs to industrial waste heat recovery at present has been the recovery of low-temperature heat from low- to hightemperature industrial flue gases (ranging in temperature from $100^{\circ} \mathrm{F}$ to $1000^{\circ} \mathrm{F}$ ) to heat water to $120^{\circ}$ to $180^{\circ} \mathrm{F}$. The low-temperature direct contact process is based on heating a water medium with hot inlet flue gas. The maximum temperature to which the water can be heated is determined by the temperature and 


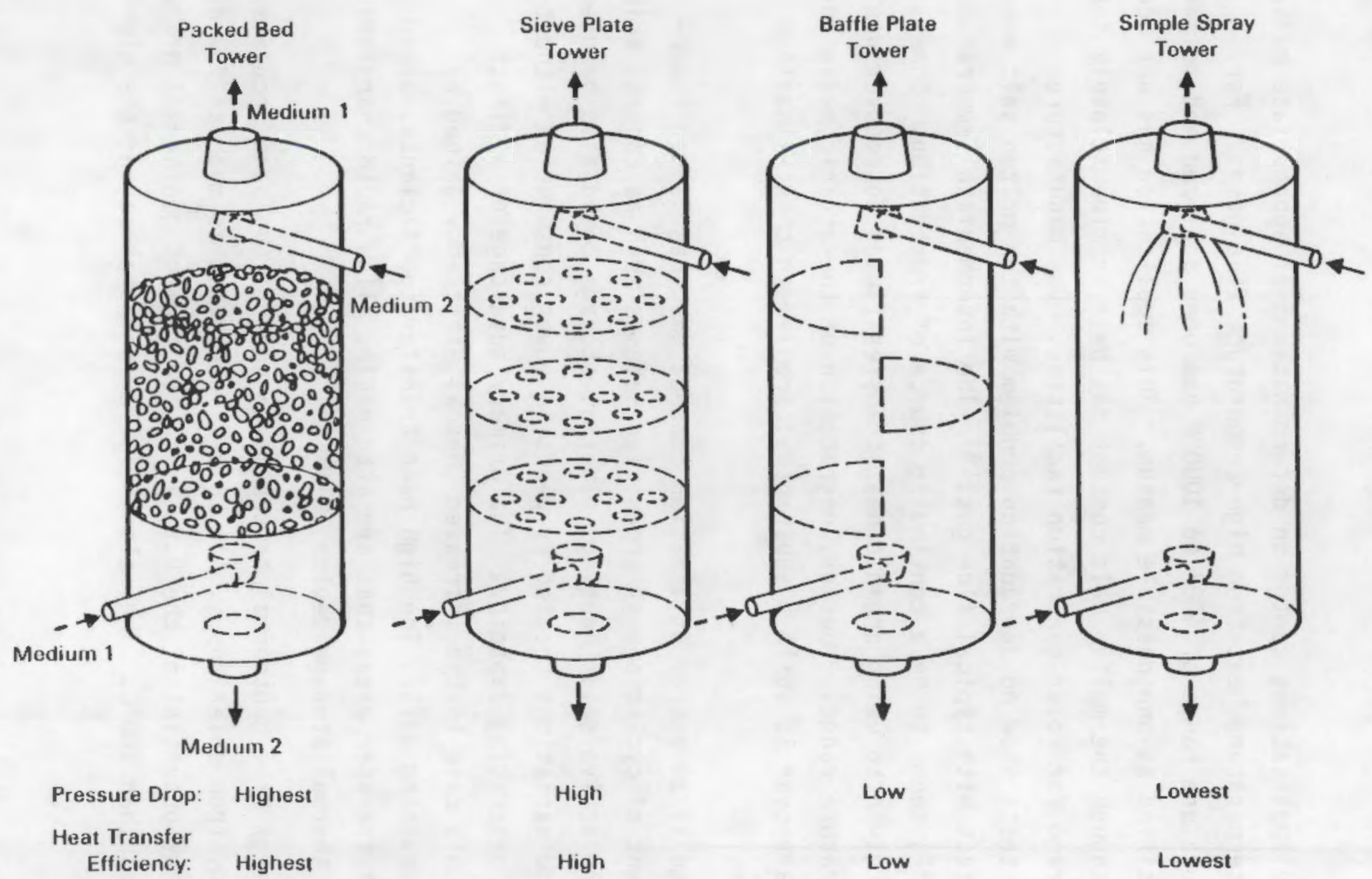

FIGURE 3.2. Internal Components in Tower Design 
relative humidity of the inlet flue gas. This process was developed and has been used worldwide since 1970 with over 3000 units installed and operating thus far. (a)

Other possible applications center on determinations of appropriate media to recover higher temperature heat from high-temperature flue gases. For instance, the temperature range of $450^{\circ}$ to $1000^{\circ} \mathrm{F}$ has been analyzed and molten salt has been identified as one possible medium. This application has not been comnercialized, although the molten salt concept has been examined closely for use in thermal storage for solar generation facilities. One manufacturer reports that their tests show no degradation problem with the molten salt when used in direct contact with typical flue gas. (a) The intermediate temperature range $\left(200^{\circ}\right.$ to $\left.450^{\circ} \mathrm{F}\right)$ seems to be a continuing source of frustration. Some attention has been given to using organic heat transfer fluids to recover waste heat in this temperature range. However, degradation of the organic media and emissions due to carryover is still a substantial problem in this technology application.

Thermal storage is an energy utilization concept that has gained importance with the advent of cyclic energy production schemes such as central solar power generation and active solar heating. Thermal storage could also be used to offset the demand variations created by peaks in power consumption without having to increase generating capacity. The primary advantage of a direct contact system in this case is the increased thermal efficiency gained by eliminating an intervening wall. The high heat transfer coefficients, along with the large heat transfer areas that are attainable, allow rapid charging/ discharging of the thermal storage device.

Extracting energy from geothermal brines poses many of the same problems as extracting energy from solar ponds. It is estimated that as much as $95 \%$ of the geothermal energy potential of the U.S. is in the form of geothermal brine at temperatures less than $200^{\circ} \mathrm{C}$. The relatively low temperature and the highly

(a) Discussion with Robert J. Goldstick, Energy Design Service, Ojai, California, December 6, 1983. 
fouling/corrosive nature of the brine make conventional heat exchangers impractical. Many direct contact systems have been designed to circumvent these probiems. Most use a countercurrent scheme where the brine is used to vaporize a saturated or halogenated hydrocarbon that has a low boiling point. The resulting vapor is used in a Rankine cycle to generate electricity.

Direct contact heat exchanger applications in solar energy production processes focus on two specific systems: solar central receivers and saltgradient solar ponds. Certain central receiver designs for producing power in a Brayton cycle, or for providing high-temperature process gas, require receiver cooling at elevated temperatures. This is accomplished by using a suitable fluid for the coolant, usually a liquid metal or molten salt. Transferring heat to the working gas at such high temperatures $\left(1000^{\circ}\right.$ to $2000^{\circ} \mathrm{F}$ ) would be difficult using a conventional heat exchanger. The idea of using a direct contact heat exchanger was conceived in which the dispersed drops of heated coolant exchange heat with a countercurrent flow of the working gas, thus eliminating any problems. In a salt-gradient solar pond, absorbed solar energy heats the highly saline water near the bottom of the pond. The heated brine (typically at temperatures between $60^{\circ}$ and $100^{\circ} \mathrm{C}$ ) is used to vaporize an appropriate working fluid to produce power in a conventional Rankine cycle. The advantages of a direct contact heat exchanger in this application stem from its superior low-temperature performance and its ability to accommodate the corrosive brine.

Many specialized applications for direct contact heat exchangers also exist because of their unique characteristics. These applications range from providing heat exchange in space power systems to the cooling of fusion reactor breeding blankets.

Direct contact heat exchangers offer important advantages over conventional exchangers by virtue of intimate media contact; for the same reason, they present drawbacks that limit their application. A major problem is media compatibility. Three fundamental criteria must be met in any workable direct contact heat exchange concept: 
1. immiscibility of the two media--no significant mass transfer

2. chemical stability--no significant chemical interaction between the two media

3. sufficient density difference between media streams.

These three requirements place considerable restrictions on the media combinations that can be used. These constraints are especially severe in hightemperature and corrosive applications where mass transfer and chemical processes are accelerated. Another consequence of direct media contact is that heat transfer must take place at the system pressure; heat exchange between fluids at dissimilar pressures is not possible. Also, because there is hydrodynamic, as well as thermal, interaction between the media, the density of throughputs must be limited to values below that which causes significant entrainment of one medium stream in the other. Insufficient differences in media densities can severely limit these attainable throughputs. Entrainment of one medium stream in another, known as carryover and carryunder in fluid/fluid systems and elutriation in solid/fluid systems, can adversely affect both thermal and economic performance. 


\subsection{STATE OF TECHNOLOGY ASSESSMENT}

In this chapter, the state of technology for each type of direct contact heat exchanger (DCHE) is assessed in detail. For purposes of this assessment, DCHEs have been classified according to the phase of the media. The types considered are: liquid/liquid, liquid/solid, liquid/gas, gas/liquid, and gas/ solid. The various DCHE types are further classified by the different application areas in which they are found. Four major application areas are identified: industrial waste heat recovery, thermal storage, geothermal energy extraction, and solar energy extraction. Specialized (other) applications are also identified. For each relevant application area within a given exchanger type, a description of the specific technology and the problems associated with $i$ is presented. The current level of implementation and the status of research are also examined. The information presented in this chapter is used as background and justification for the R\&D needs identified for this technology.

\subsection{LIQUID/LIQUID}

The liquid/liquid direct contact heat exchangers (LLDCHEs) reviewed below include those applied to industrial waste heat recovery, geothermal, solar, and other (specialized) systems. In this case, the specialized application is the production of fresh water by desalination and the LLDCHEs are used to induce phase change in salt water (either by freezing or boiling) to obtain pure water.

\subsubsection{Industrial Waste Heat Recovery}

Use of LLDCHEs for recovery of waste heat is not as extensive as that of gas/liquid or gas/solid types. This is because most waste heat streams of useful energy content are in gaseous rather than liquid form. However, one system developed by Hitachi Limited of Japan uses an intermediate oil loop to transfer heat from an exhaust gas stream to an organic working fluid. (a) in

(a) An Assessment of Energy Saving Technologies with Potential for Applications in U.S. Industries. Unpublished report by Fuel and Energy Consultants Inc. prepared for U.S. DOE Office of Industrial Programs, January 1982, pp. 69-72. 
this LLDCHE design, heat is transferred from a gaseous waste heat stream at approximately $500^{\circ} \mathrm{F}$ to a specially developed high-temperature oil in a conventiona 1 recuperator. The heated oil is used to vaporize the freon $R-113$ working fluid in a direct contact boiler and is then cycled back to the recuperator. The freon vapor is routed to a turbine/ generator to produce electricity, condensed back to liquid form, and returned to the preheater and direct contact boiler. The power output of the system is $3,000 \mathrm{~kW}$ at a waste gas flow rate of $283,000 \mathrm{cfm}$. (a) The boiler configuration is cylindrical with the freon working fluid sprayed into the oil by means of injector pipes situated both parallel and transverse to the vessel's long axis. Liquid R-113 is known to be denser than the oil, although specific details of the flow inside the boiler are not well understood.

By using this binary fluid approach to freon vaporization rather than direct vaporization by the waste heat stream, freon decomposition is avoided. This is desirable because ionized chlorine released by breakdown of R-113 is highly corrosive. (b) The system is presently being tested at a cement plant in Japan. (a) The principal problem with the system is its economic performance, although specific factors affecting this performance have not been identified. Hitachi representatives believe that an economical system can be developed using the direct contact exchanger. (a) Consequentiy, research is under way to improve overal1 system economics.

\subsubsection{Geothermal}

Electrical power generation from hot geothermal brines is the area in which LLDCHEs have seen the greatest application. The many various geothermal systems all use geothermal brine to vaporize a low boiling point working fluid. A conventional Rankine cycle is employed to generate electricity. Use of OCHEs in geothermal power production was first advocated in 1973 by Jacobs and Boehm

(a) Telephone discussion with S. Sakaguchi, Hitachi Limited, Ibaraki, Japan.

(b) An Assessment of Energy Saving Technologies with Potentia? for Applications in U.S. Industries. Unpublished report by Fuel and Energy ConsuTtants Inc. prepared for J.S. Department of Energy Office of Industrial Programs, January 1982, pp. 69-72. 
of the University of Utah (Jacobs and Boehm 1980). They suggested that direct contact units would avoid the fouling problems associated with conventional exchangers and would provide improved thermal performance.

Geothermal LLDCHE systems can be divided into two categories: 1) those that preheat (brining to saturation) and boil the working fluid in the same exchanger, and 2) those that preheat and boil in separate exchangers. Boehm et a1. (1983) suggest that separation of the two processes could provide capital savings over the integral (combined) approach. However, the majority of systems that have been built and tested use integral preheat/botling. For this reason, and because the basic phenomena that occur are essentially the same for the two types, only the integral preheat/boil systems are considered in this report.

The integral preheat/boil LLDCHEs can be further divided: 1) designs having no "internals"--the simple spray or Elgin tower, and 2) designs with internal components that improve hydraulic and heat transfer performance. A primary consideration for both types is the choice of working fluid. An idea? working fluid has a high vapor energy density to minimize turbine size and maximize cycle efficiency and a low solubility in the brine to minimize working fluid losses from the system. Potential working fluids that have been considered are light hydrocarbons and halogenated hydrocarbons (freons). Of the two, the light hydrocarbons are usually favored because of the relative expense and adverse environmental impact of the freons. (a) Most studies have shown that at brine temperatures above $300^{\circ} \mathrm{F}$, isobutane provides the highest utilization factor (watt-hr/lb brine flow) (Nichols et al. 1980; Fulton 1978; Nichols and Prigmore 1981). (b) At lower brine temperatures, pentane cycles become competitive. Use of hydrocarbon mixtures has also been investigated. However, exchanger performance using mixtures is generally poorer than with pure working fluids (Mines, Demuth and Wiggins 1983).

(a) Telephone discussion with H. R. Jacobs, University of Utah.

(b) Telephone discussion with B. Olander, Barber-Nichols Engineering, Arvada, Colorado. 
Typical of the first type of LLDCHE (the spray tower) is the $500 \mathrm{~kW}$ direct contact exchanger designed by Barber-Nichols Engineering and operated at the East Mesa Geothermal Field (Nichols et al. 1980; Nichols and Prigmore 1981; Nichols 1981; Nichols et a1. 1981). The exchanger is a column approximately 40 $\mathrm{ft}$ high and $40 \mathrm{in}$. in diameter. About $30 \mathrm{ft}$ of the total length is occupied by the downward flowing brine, which is introduced just below the free surface. Liquid isobutane is injected at the bottom of the column through a distributor plate. Because the two fluids are of different density, the bubbles of dispersed isobutane rise through the brine column where they eventually reach the saturation temperature of $250^{\circ} \mathrm{F}$ at the system pressure of $435 \mathrm{psia}$. The isobutane vapor is superheated an additional $5^{\circ} \mathrm{F}$ by the brine before being drawn of $f$ to produce power in the turbine/generator. In the process of transferring heat to the isobutane, the brine is cooled to approximately $130^{\circ} \mathrm{F}$. Pinch points (smallest temperature difference between fluids) of $1^{\circ}$ to $5^{\circ} \mathrm{F}$ have been obtained in the column (Nichols 1981). Before being introduced into the exchanger, the brine is treated in a flash tank to remove noncondensibles that would inhibit performance by diffusing into the isobutane vapor and building up in the condenser. The brine is then brought to system pressure by a boost pump before being injected into the exchanger. After exchanging heat in the column, the brine is vacuum stripped to recover any dissolved or entrained isobutane. The recovered working fluid is returned to the condenser for reuse in the cycle.

Internals can be added to the basic spray tower to improve its thermal performance. The internals serve to increase the heat transfer area and/or the volumetric heat transfer coefficient between the phases. Several different designs using internals have been proposed (Jacobs 1977). The $60 \mathrm{~kW}$ Sieve Tray LLDCHE operated by EG\&G at the Raft River geothermal test site in southern Idaho is an example of one design that uses internals (Whitlock 1981; Mines 1982; Wiggins, Mines and Wah1 1982). The exchanger is a column $19.5 \mathrm{ft}$ tall and $1 \mathrm{ft}$ in diameter. As with the Barber-Nichols exchanger, the hot geothermal brine is injected at the top of the column and the liquid isobutane at the bottom. However, the column also contains 19 sieve trays that act to coalesce the isobutane droplets and redisperse them. Much higher heat transfer coefficients are attained by this repeated formation of droplets (Culbreth, Johnson 
and Marschall 1981). Seventeen trays are used to preheat the isobutane to saturation and two trays are used for boiling and superheating. Results with the Sieve Tray LLDCHE show the efficiency in the preheat section is $50 \%$ higher than that of a spray tower and $200 \%$ higher in the boiling section (Wiggins, Mines and Waht 1982). Pinch points of less than $0.1^{\circ} \mathrm{F}$ have been obtained with this device.

Despite their apparent success, geothermal LLDCHEs exhibit many technological problems. Backmixing occurs in spray towers and, to a lesser extent, in sieve tray exchangers when cold brine from the tower bottom is entrained in the flow of the rising isobutane drops and is transported to the top. There the cold brine mixes with the hot, incoming brine. The resulting temperature drop reduces the efficiency of the exchanger (Suratt and Hart 1977).

Backmixing is a function of both the exchanger holdup (percentage of column volume occupied by working fluid droplets) and column height-to-diameter $(H / D)$ ratio. To avoid excessive backmixing, $H / D$ values less than 10 are not recommended for use in spray towers (Della Vida, Franz and Weinreich 1980). Test results from the Barber-Nichols $500 \mathrm{~kW} \mathrm{LLDCHE,} \mathrm{which} \mathrm{has} \mathrm{an} \mathrm{H/D} \mathrm{of} \mathrm{about}$ 90, confirm that backmixing is not significant (Nichols and Prigmore 1981).

Carryunder or flooding is the entrainment of the isobutane droplets in the brine flow out of the exchanger. Carryunder places an upper limit on the allowable throughputs in the system. This limit can be increased by expanding the diameter of the column. However, expanding the diameter of the vessel must be tempered by the possibility of increased backmixing. Thus, performance tradeoffs are an important consideration in design.

Achieving proper distribution of the working fluid in the column is another major difficulty. (a) Obtaining droplets of uniforin size at significant isobutane flow rates is difficult due to the nature of droplet formation. At relatively large flow rates, droplets are formed by random breakup of working fluid jets. This process results in a distribution of droplet sizes. To avoid excessive carryunder and backmixing, the smaliest expected droplet size is used in design calculations. However, design optimization is difficult because

(a) Telephone discussion with H. R. Jacobs, University of Utah. 
there are presently no models that can predict the droplet size distribution (Mines, Demuth and Wigging 1983). Additionally, designs based on an arbitrary selection of minimum droplet size can be overly conservative.

The entire range of problens calls into question the suitability of existing models for design of LLDCHEs. Many researchers believe that present theoretical models for treating the thermal and hydraulic phenomena that occur in liquid/liquid systems are inadequate. (a,b) Improved models are necessary if optimized designs are to be attained. In particular, theories that adequately describe the multi-drop boiling process (Jacobs et al. 1977) and predict working fluid droplet size (Mines, Demuth and Wiggins 1983) are lacking.

Because isobutane is not perfectly immiscible in the brine, and since the processes of heat transfer and mass transfer are coupled, a certain amount of isobutane dissolves in the brine and is carried out of the system. The amount of dissolved isobutane depends primarily on the salinity of the brine, the isobutane flow rate, and the diameter of the isobutane droplet (Knight and Perona 1981). In genera1, increasing tower height to achieve higher heat transfer efficiencies results in increased isobutane 10ss. It has been estimated that the loss of $250 \mathrm{ppm}$ of isobutane in the outgoing brine would result in a replacement cost of $\$ 1.2$ million per year for a 50 MWe plant (Nichols and Prigmore 1981). It is evident that some sort of working fluid recovery scheme must be employed in any practical system. In fact, the cost of the equipment required to limit loss of working fluid from the system is one of the major factors influencing plant performance and economics (Nichols and Prigmore 1981).

In addition to treatment of the outgoing brine, the incoming brine must be treated to remove any noncondensibles in the flow. Noncondensibles present in the influent brine can diffuse into the isobutane vapor, reducing system efficiency by increasing turbine backpressure and interfering with condensation of the working fluid in the condenser. As with working fluid recovery, brine treatment to remove noncondensibles introduces additional costs to the system.

(a) Telephone discussion with H. R. Jacobs, Universtty of Utah.

(b) Telephone discussion with G. L. Mines, EG\&G, Idaho Falls, Idaho. 
There are other general problems that arise with LLDCHEs. Because of the susceptibility of the equipment to fouling by the brine, additional equipment is necessary for operation of a geothermal LLDCHE. Problems with fouling of boost pumps, valves, and hydrautic turbines in the Barber-Nichols exchanger was a major concern. (a) The flammable nature of isobutane presents a safety problem that necessitates strict measures to minimize the possibility of fire or explosion. This flammability hazard creates additional expense for items such as explosion-proof motors, fire control equipment, and leak detectors.

The sieve tray exchanger presents some unique problems of its own. The presence of internals resurrects fouling concerns. The thermal/hydraulic aspects of the trays are not well understood and various occurrences can lead to radical deterioration of column performance (Mines, Demuth and Wiggins 1983). Control problems have been experienced due to the large amount of isobutane near saturation in the column (Mines, Derruth and Wiggins 1983). Any decrease in system pressure causes large scale boiling that results in a level swell. Automatic operation of the levei control valve decreases pressure further, exacerbating the problem. Eventual flooding of the column and excessive loss of working fluid.

While geothermal LLDCHEs have been studied extensively in the past, the current effort in this area is very modest. $(a, b, c, d, e)$ This is largely due to decreased funding for basic research by the various government agencies involved. The Barber-Nichols $500 \mathrm{~kW}$ exchanger has been mothballed (a) and the EG\&G sieve exchanger is not presently being operated. (d) Successful use of anti-scalants in conventional heat exchangers appears to have taken away some of the impetus for development of direct contact units. (a) This has led many to believe that for relatively clean brines, conventional heat exchanger use is favored. $(d, e)$

(a) Telephone discussion with B. 01 ander, Barber-Nichols Engineering, Arvada, Colorado.

(b) Telephone discussion with R. Boehm, University of Utah, Salt Lake, City, utah.

(c) Telephone discussion with H. R. Jacobs, University of Utah, Salt Lake, City, Utah.

(d) Telephone discussion with G. L. Mines, EG\&G Idaho, Idaho Falls, Idaho.

(e) Telephone discussion with I. Sheinbaum, I. Sheinbaum Co., Pasadena, California. 


\section{1 .3 Solar}

Two different LLOCHEs have been identified for potential application to solar technology. The first system extracts thermal energy from a saitgradient solar pond and converts it to electrical power. It is essentially identical to the geothermal LLDCHEs except that pentane is used as the working fluid rather than isobutane. The second system heats water using diethyl phthalate (DEP) as the heat collection and transfer fluid.

Brine removed from the bottom layer of a salt-gradient solar pond is typically at a temperature of between $60^{\circ}$ and $100^{\circ} \mathrm{C}$. Extracting energy from this brine is a low-efficiency process due to the relatively small temperature difference between the heat source and the heat sink. Consequently, a major portion of the capital expense involved in such a system is the heat exchanger.

Due to its improved thermal performance over conventional heat exchangers, direct contact technology has the potential for reducing total plant cost by as much as 25\% (Wright 1981 and 1982). (a) A conceptual design for such an exchanger was developed by SERI (Wright 1981 and 1982). The exchanger is a spray tower with internal packing added to suppress backmixing and to improve heat transfer. Liquid pentane is introduced at the bottom and heated brine at the top. Pentane is used as the working fluid because it exhibits the highest cycle efficiency at the brine temperatures encountered (Wright 1981). Pentane vapor is drawn from the top of the coluinn and generates electricity in a conventional Rankine cycle.

The technical problems facing this liquid/liquid system are the same as those listed for the geothermal systems. The large uncertainties that exist in the available theoretical thermal and hydrodynamic models make design optimization difficult or impossible (Wright 1982). A particularly important question centers on the equilibrium vapor bubble size in the boiling section. The size, configuration, and cost of the exchanger depends primarily on the maximum allowable superficial vapor velocity, which is in turn a function of the equilibrium vapor bubble size (Wright 1982). Questions concerning working fluid

(a) Telephone discussion with J. D. Wright, SERI, Golden, Colorado. 
flow in a packed column remain unanswered. The possibility exists that slugs of vaporized pentane could penetrate the column and cause localized flooding, thus adversely affecting heat exchanger operation and performance.

As with the geothermal liquid/liquid systems, the current volume of research on solar applications of liquid/liquid systems is very small because of decreases in federal funding. (a) A test-scale exchanger has been built at the University of Utah under SERI sponsorship to study some of the unanswered questions mentioned previously. However, it is not currently being operated.(b) Unlike geothermal application, the advantages offered by direct contact exchangers (over alternative methods) for extraction of energy from solar ponds are clear. Their superior low-temperature performance and economics make them the only choice for this application. (a)

A LLDCHE that is essentially a solar hot water heater has been developed by the Solar Energy Applications Laboratory at Colorado State University (Kuraki and Brothers 1980). Since the heat transfer fluid, diethyl phthalate (DEP), is heavier than water, the exchanger operates in typical spray tower fashion with the dispersed phase falling through the column. The DEP fluid is heated in solar collectors and routed to the exchanger where it is dispersed into droplets. As these droplets fall through the column, they exchange heat to the water by direct contact. The droplets are coalesced at the bottom of the exchanger and the DEP is pumped back to the collectors for another cycie.

The primary disadvantage of the system is the amount of power needed to pump the viscous DEP fluid (Kuraki and Brothers 1980). Although the system exhibited a performance advantage over one using a conventional water heater (with an ethylene glycol/ water mixture as the heat transfer fluid), this advantage was not sufficient to overcome the higher capital and operating costs.

\subsubsection{0ther}

Production of fresh water by desalination can be accomplished by either freezing or boiling (distilling) sea water. Direct contact systems have been

(a) Telephone discussion with J. D. Wright, SERI, Golden, Colorado.

(b) Telephone discussion with H. R. Jacobs, University of Utah. 
designed using both methods (Somer et al. 1973; Sideman and Gatey 1966). The distillation method, however, seems to be more popular (Somer et al. 1973).

One system developed at the Middle East Technical University in Ankara, Turkey, promotes distillation by bringing sea water directiy into contact with hot $0 i 1$ (Somer et al. 1973). The incoming brine is preheated by circulating through the evaporator shell and is then sprayed onto the hot oil surface. Between $80 \%$ and $85 \%$ of the brine is evaporated. The water vapor is routed through an entrainment separator and a cyclone to remove entrained drops of sea water and oil. Some oil, however, is still carried over and is separated by floatation after the vapor flow condenses. An absorption column is necessary to remove the approximately $100 \mathrm{ppm}$ of oil dissolved in the condensate. The concentrated brine-oil mixture is routed to a cyclone for separation; the brine is discarded and the oil is reheated and pumped back to the evaporator.

The performance of this unit was considered very satisfactory (Somer et a1. 1973). One problem encountered was foaming in the evaporator. This was effectively dealt with by adding an anti-foaming agent. It is not known how this affected the water quality.

As far as the current level of implementation and R\&D of these systems, not much is known, and little information was available through domestic sources. However, the technology is ten years old. This leads one to conclude that in the United States the current level of interest in this technology is not very great. The fact that most work in desalination has been performed outside the U.S. may also reflect the relative disinterest domesticaliy in desalination in general.

\subsection{LIQUID/SOLID}

The use of liquid/solid DCHEs seems to be limited to one application area: thermal storage. Therma $i$ storage has been gaining importance with the increased emphasis on energy conservation and with the advent of cyciic energy production systems such as solar power and heating systems. In all the systems reviewed, a heat transfer fluid transfers heat to and from a heat storage medium that is initially solid. The systems all take advantage of the storage medium's latent heat of fusion to attain high volumetric energy storage 
capacities. Because heat storage is accomplished by inducing change of phase, heat transfer takes place at a relatively constant temperature. Energy storage at a desired temperature can therefore be obtained by proper selection of the storage medium. In two of the systems identified, the heat transfer fluid undergoes phase change as well. These systems are all described in the text that follows.

\subsubsection{Thermal Storage}

Three of the four systems reviewed are similar in that they use some variety of salt hydrate as the storage medium. One of the three salt systems uses a petroleum oil as the heat transfer fluid; no phase change of this oil occurs. The remaining two salt systems use freon as the heat transfer fluid; phase change occurs by reflux bolling during discharge. The fourth system is unique in that it employs a form-stable variety of polyethylene to store heat. Ethylene glycol is the heat transfer fluid.

The Electrotechnical Laboratory in Ibaraki, Japan, has developed a novel liquid/solid direct contact thermal storage unit in which the storage medium undergoes change of phase but does not lose its physical integrity (Abe et a1. 1983). The storage medium consists of rods of high density polyethylene (4 mm in diameter and $40 \mathrm{~cm}$ in length) that have been form-stabilized by ion plasma bombardment. The rods are arranged into bundles $16 \mathrm{~cm}$ in diameter; two bundles are stacked axially in the storage column. The heat transfer fluid, ethylene glycol, flows axidlly along the rods. When charging, the flow enters from the top and when discharging the flow enters from the bottom. Phase change of the polyethylene occurs at $260^{\circ} \mathrm{F}$. With $9 \mathrm{~kg}$ of polyethylene, a heat storage capacity of $1623 \mathrm{~kJ}$ is realized. A problem encountered with this device is deformation of the storage bundle in the charged state. Even though the polyethylene rods are formustabilized, they lose much of their structural rigidity in the liquid state.

In general, the salt hydrate systems, store heat at lower temperatures (between $80^{\circ}$ and $140^{\circ} \mathrm{F}$ ) because of their lower melting points. A device developed by OEM products known as a heat battery is designed to store heat for residential heating by using off-peak electricity (Carlsson and Schmidt 
1981). (a,b) Hydrate sodium sulfate (Glauber's salt) is the heat storage medium and a petroleum oil is the heat transfer fluid. Conventional electrical resistance elements heat a water loop which in turn heats the oil by means of an immersed heat exchanger. The heated oil is circulated through the tank, causing the salt to melt. Phase change of the storage medium takes place at $90^{\circ} \mathrm{F}$. A heat pump on the water loop extracts heat from the system during thermal discharge. The operating temperature of the unit also makes it compatible with other heat sources, such as waste heat from air conditioning (Parkinson 1980) and solar heating systems. (b) The workability of this device has been demonstrated in actual field tests sponsored by TVA. However, problems were encountered with tank corrosion. Addition of polymer and fiberglass linings did not correct the problem. Continued tank leaks resulted in early termination of the field tests. $(a, b)$

Researchers at the Royal Institute of Technology in Stockholm, Sweden, have tested a system in which both the heat storage medium and the heat transfer fluid undergo phase change (Carlsson and Schmidt 1981). The advantage of allowing the heat transfer fluid to vaporize is that mixing and regulation of the thermal output is accomplished in a passive manner rather than by forced circulation. A combination of hydrated calcium chloride and strontium chloride is the heat storage medium. Melting occurs at $86^{\circ} \mathrm{F}$. Either freon R-113 or R-1282 is used as the heat transfer fluid. The system is charged by means of a water jacket surrounding the storage tank. Reflux boiling of the freon by the liquefied salt creates freon vapor as heat is extracted, the freon vapor condenses. Although system performance was judged to be good, a number of technical difficulties exist. Rapid discharging results in solidification of the surface of the storage medium. This impedes vapor flow to the condenser and prevents further heat extraction. Noncondensibles in the freon condenser also impede heat removal. Shock boiling of the freon can cause severe mechanical

\footnotetext{
(a) "Operating Experience with Offpeak Brick Furnaces, Pressurized Water Systems, and Eutectic Salt Systems," TVA preliminary project findings.

(b) Telephone discussion with Edward L. Colston, TVA, Chattanooga, Tennessee.
} 
strains on the system. The researchers state that provisions for forced circulation of the freon vapor through the storage tank could possibly correct these difficulties.

TES, Inc., of San Diego is developing a system whose basic process for thermal storage is similar to that of the Swedish system. (a,b) Researchers there are currently working to identify optimum heat storage/transfer media combinations for storage of low-grade heat in the temperature range of $100^{\circ}$ to $180^{\circ} \mathrm{F}$. Industrial processes requiring low-grade heat and commercial heating are viewed as the main potential applications. Several salt hydrates are being considered for their properties at the temperature range of interest. A 1aboratory scale unit is currently operating to assist these investigations, and a prototype scale unit is being designed. (a) Present concerns focus on the hydrostatic pressure gradient that exists in the unit and its effect on the heat transfer between the storage medium and the heat transfer fluid.

\subsection{LIQUID/GAS (GAS DISPERSED)}

In liquid/gas DCHEs, heat transfer occurs between a gas and a liquid medium. The term "liquid/gas" implies that liquid occupies the bulk of the volume while gas is dispersed within the liquid medium. Several application areas have been identified in this classification. These applications involve novel methods for heating liquids with combustion gases. This technology is treated in the "other" category, although it is believed to have potential for industrial waste heat recovery as well.

\subsubsection{Other}

Submerged combustion for heating water is one area in which liquid/gas direct contact technology has been applied. In the generic design, exhaust gases from an aboveground burner are directed to the bottom of a tank filled with water. The gases are distributed through an inlet manifold; this results in hot bubbles of gas that rise through the vessel. In this manner, heat is transmitted directly from the gas to the liquid medium.

(a) Telephone discussion with Victor Ott, TES, Inc., San Diego, California.

(b) Telephone discussion with B. Thielbar, DoE-Idaho, Idaho Falis, Idaho. 
The submerged combustion direct contact heating process was originally developed to reheat liquefied natural gas. A European (French) company is now manufacturing submerged combustion units that can be used in phosphitationdegreasing (metal cleaning). Five such units are already in operation. Additional heat transfer applications of this technology were developed for direct contact heating of pickling liquors and other highly corrosive liquids. (a) Several problems occurred however. Specifically, "hot spots" developed in the tower, and pollution emissions became a problem. Nevertheless, it seems that the principal impetus to adopt submerged combustion technology in these applications is to increase efficiency at the same time the liquid-side fouling and corrosion problems that would occur in the proximity of boiler tubes are circunvented.

Unlike typical countercurrent tower designs, thermodynamic limitations generally require that the water temperature can never be higher than the exhaust (i.e., exiting the DCHE) gas temperature. Another drawback is that an energy penalty is paid in the price of pressure drops that occur with these designs. Nevertheless, for low-temperature water heating (i.e., less than $120^{\circ} \mathrm{F}$ ), the simplicity of design, low capital cost, and high efficiencies make submerged combustion an attractive alternative to conventional water heating methods. The reader is referred to the GRI report (Goldstick and KUB, Inc. 1981) for a listing of U.S. and foreign suppliers of the equipment and for more comprehensive handling of the pros and cons and applications of the technology.

A vortex flow system designed mainly for heating water was investigated by researchers at the University of Calgary (Rao and Mohtadi 1983). To produce hot combustion gases, natural gas is burned in the naturally occurring air core created within a hydrocycione. Downstream of the flame, efficient mixing of the hot gases and water produces a mist in which a near-complete recovery of heat is accomplished. Advantages include high heat transfer efficiencies and compact size.

(a) Discussion with Robert J. Goldstick, Energy Design Services, Ojai, California, December 6, 1983. 
The system described above can offer several advantages to alternative water heating methods. In comparison to spray, tray, and packed bed direct contact gas coolers, flooding and pressure drop considerations are less of a concern when operating at high superficial gas velocities. Furthermore, when hot exhaust gases are fed directly to a tray or to a packed column, the need for high temperature materials for trays and packing will add substantially to the cost of these units. These limitations are minimized by carrying out combustion directly in a flowing stream of water. By keeping the combustion zone itself surrounded by incoming cold water, one can minimize both the heat loss and the need for high-temperature materials. This latter point also applies to the comparison between the system presented here and conventional submerged combustion equipment.

Specific problems with the technology were not readily identified. Experiment results indicated no major flaws with the system. The developers of the vortex flow DCHE believe that the system can be applied to a wide range of industrial applications. Several of these applications include: reaction gas quenchers, fractionator condensers, submerged combustion water heaters, and downhole steam generators.

There is strong incentive to further investigate the potential advantages of using liquid/gas systems in place of the more common gas/liquid systems. (a) High heat transfer coefficients and efficiencies are possible with "bubble-up" (1iquid/gas direct contact units). Also, because contact times are often much shorter than in spray towers, mass transfer from the gas to the liquid (in this case, water) can be more easily controlled. Thus, it is possible to guard against water contamination or even to remove selected components in the gas stream. However, additional basic RaD is needed to distinguish between heat transfer and mass transfer rates of select media components. Essentially, the basic question must be asked, "Is mass transfer desirable in a particular application, and if so, to what extent?"

(a) Telephone discussion with H. R. Jacobs, University of Utah. 


\subsection{GAS/LIQUID (LIQUID DISPERSED)}

Gas/liquid direct contact heat exchangers facilitate heat transfer between a gas and a liquid medium. The term "gas/liquid" implies that gas occupies the bulk of the volume while liquid is dispersed within the gas medium.

Within the domain of gas/liquid DCHE's, several application areas are identified and reported in this section of the report. These application areas include: 1) industrial waste heat recovery, 2) thermal storage, 3) solar, and 4) other systems. The "other" system addressed in this section is a thermal management system of space power systems of various types. The order in which these application areas are presented and discussed does not reflect an implied level of importance.

\subsubsection{Industrial Waste Heat Recovery}

By and large, the greatest application of gas/liquid DCHE's has been to recover waste heat from industrial exhaust gases. In its inst common form, water acts as the second medium to which heat is transferred from hot exhaust gases in a direct contact scheme.

Conventional heat exchanger equipment cannot of ten be used costeffectively to recover heat from fouling and corrosive exhaust gases. In conventional equipment, if the temperature of the gas-side stream is reduced below the acid dew point, condensation of acids contained in the exhaust gases can cause deterioration of the heat exchanger. To prevent cold-end corrosion, flue gas can often only be cooled to about $240^{\circ}$ to $300^{\circ} \mathrm{F}$ (Mullin 1983).

In all fairness to the manufacturers of conventional heat exchanger equipment, it should be noted that increases in energy prices have resulted in many positive changes to conventional designs that help mitigate the harmful effects of acid condensation in these units. Several of these improvements make use of modular designs, whereby flue gases can be cooled to as low as $110^{\circ}$ to $120^{\circ} \mathrm{F}$ (a) In the modular approach, the last stage(s) are removable and can be easily replaced. Since acid condensation does not occur until these final

(a) Discussion with Robert J. Goidstick, Energy Design Services, 0jai, California, December 6, 1983. 
stages, only the removable end pieces need be replaced. Alternatively, these end modules can be made of high-priced, corrosion-resistant materials such as stainless steel, teflon-coated steel, or glass materials. Because only the end pieces are constructed of these materials, substantial cost savings can be realized in comparison to designs that use these materials throughout. However, these units are still expensive because of the materiais required. ATso, indirect heat transfer in this low temperature regime has a low driving force and requires large surface areas, and this contributes further to materials costs. Nevertheless, these modular designs are commercially produced and they are being used.

Direct contact heat exchangers can be used where conventional heat exchangers are not practical or desirable. Because the material requirements are less, direct contact units can be constructed from high cost, corrosionresistant materials. In this fashion, latent heat from condensation, as well as sensible heat, can be extracted from the exhaust gases, and the temperature of the exhaust gas can be brought within $5^{\circ}$ to $10^{\circ} \mathrm{F}$ of the incoming water temperature; some applications result in gas temperatures as low as $65^{\circ}$ to $75^{\circ} \mathrm{F}$ (Mullin 1983). Direct contact systems of this type are often termed "condensation heat recovery" systems because they can be used to recover latent heat (although at a lower temperature) and thus greatiy increase the total energy recovered. Since the main purpose of such systems is to recover heat rather than function strictly as a condenser (because of process requirements), they are included for discussion here. Conventional condensers are omitted from discussion by definition (see Chapter 2.0).

Use of water as the working fluid in the direct contact heat transfer process results in a temperature limitation in the range of $120^{\circ}$ to $180^{\circ} \mathrm{F}$. The process can be described as follows. The flue gas enters the bottom of the tower and goes into what is appropriately labeled the humidification zone. Water that has passed down the column is vaporized and the flue gas cools; most of the heat at this point vaporizes rather than heats the water. When the flue gas has reached saturation and moves further up the tower, the water vapor begins to condense and heat the oncoming water. It must be remembered that flows are countercurrent to one another and water higher in the tower is at 
lower temperature. Condensation continues until the flue gas exiting the tower contains less water than the flue gas entering the tower. The adiabatic saturation temperature represents the maximun temperature to which the liquid can be heated. This temperature is determined by the inlet temperature and the humidity of the flue gas. Therefore, the flue gas entering the DCHE at $1800^{\circ}$ to $2000^{\circ} \mathrm{F}$ can heat hot water in the $180^{\circ}$ to $190^{\circ} \mathrm{F}$ range, whereas flue gas from a typical gas- or oil-fired boiler can result in temperatures in the $135^{\circ}$ to $145^{\circ}$ temperature range. Other industrial applications, such as dryer heat recovery, allow for higher hot water temperatures because the flue gas from the dryer has a much higher water content and therefore a higher adiabatic saturation temperature. (a)

Additional benefits of such systems include the cleansing or scrubbing action of the liquid on the dirty gaseous exhaust stream, particularly in the cases of oil-or coal-fired boilers. Particulates and soluble contaminants are removed during this heat recovery step. However, in some cases this is not desirable. In these latter cases, a two-stage, direct/indirect system is used.

In the two-stage process, hot water that is produced from direct contact with a dirty exhaust gas is directed through a conventional heat exchanger to heat a second liquid (i.e., water). The direct contact process is isolated from the rest of the process, but through direct contact heat exchanging, full latent heat from condensation can be recovered from the exhaust gases and gasside fouling can be minimized. (a) Nevertheless, this increase in energy recovery must be balanced against increases in capital cost and erosion of efficiencies caused by the use of indirect heat exchangers.

Essentially, three types of direct contact devices have been widely applied commercially for industrial waste heat recovery: spray towers, baffle plate towers, and packed-bed towers. The choice of which type of tower to use is determined primarily by the application. The spray tower has the lowest pressure drop and the lowest thermal performance. It is ideal for very small applications in the 2 to $10 \mathrm{million}$ Btu/hr range. The packed tower represents

(a) Discussion with Robert J. Goldstick, Energy Design Services, Ojai, California, December 6, 1983. 
the other extreme. The heat transfer thermal efficiency is very good, but it also has the highest pressure drop (in the range of 3 to 5 inches of water). These systems are generally reserved for very large applications. The baffie plate tower represents a balance between the two, and as a result, has seen the widest range of application. Other direct contact devices used to a lesser extent include cross-flow tray columns and co-current pipelines (the tray columns have been used in Sweden to recover heat from black 1iquor recovery boilers) (Goldstick and KVB, Inc., 1981). One system under development employs tubular textile bundles over which water flows; heat transfer is accomplished between a hot gas passing over the bundles and the water. (a)

Specific problems of this technology seem to revolve around the constraints imposed by economics of the system, dictated to a large degree by fuel prices, and by the need for large quantities of low-temperature heat (i.e., $135^{\circ} \mathrm{F}$ ) throughout the industrial site. Because water is used as liquid medium, and because of the temperature constraints imposed, the system cannot be used to capture high-temperature, high-quality energy. But the efficiencies attainable at a low-temperature recovery are unsurpassed by alternate methods.

Typical uses for the low-temperature heat are process preheating, space heating, and domestic hot water heating. It has been suggested that district heating be examined as a possible end use for the low temperature heat recovered through this type system, although considerable research is needed to determine the feasibility/practicality of this idea. Also, because temperatures in the $160^{\circ}$ to $180^{\circ}$ range are attainable, it is possible to produce electricity with about $17 \%$ to $18 \%$ conversion efficiency using available heat engines such as the heat engine developed by Kinetics in Sarasota, Florida. (b) If the Nitinol engine were ever proven conmercially viable, possibly it could have major potential for coupling lower temperature heat recovery $\left(120^{\circ}\right.$ to $130^{\circ} \mathrm{F}$ ) with electricity production.

(a) An Assessment of Energy Saving Technologies with Potential for Applications in U.S. Industries. Unpubi ished report by Fuel and Energy Consuttants Inc. prepared for U.S. 00E office of Industrial Programs, January 1982, pp. 65-68.

(b) Discussion with Robert J. Goldstick, Energy Design Service, Ojai, California, December 6, 1983. 
Despite the current utilization restraints with these condensation heat recovery systems, over 200 units have been installed in the U.S. over the last several years and over 3000 have installed in Europe (Mullin 1983). Users report fuel savings in the range of $10 \%$ to $30 \%$. (a)

An additional application of direct contact gas/liquid heat exchangers for waste heat recovery has been studied in connection with the development of the Biphase turbine (Helgeson and Studhalter 1981). The Biphase turbine is a device that can utilize heated gas/liquid mixtures directly to produce mechanical and, if desired, electrical energy. Conventional turbines cannot handle two-phase mixtures or fouling and corrosive exhaust gases. In the design studied, exhaust gases from a diesel cycle would be used to heat an organic working fluid in a direct contact heat exchanger. The heated working fluid would then be injected through a nozzle along with water that would vaporize and expand, propelling the working fluid while imparting to it kinetic energy that is used to partially drive the turbine. The remainder of the driving component would come from the vapor pressure. The U.S. Department of Energy sponsored a study aimed at determining appropriate and compatible working fluids for the diesel exhaust environment. $(b, c)$ Researchers were not able to identify a suitable working fluid that possessed the necessary characteristics for this application. (b,c) Specifically, the most promising working fluid under examination demonstrated evaporation tendencies at the temperatures studied. The resulting evaporation layers surrounding each droplet caused a decrease in both the heat transfer coefficients and overall heat transfer efficiency. (c) Identification and testing of suitable working fluids and characterization of these fluids for different temperature and chemical environments is a high priority if direct contact technology coupled to the Biphase turbine is to become widely marketable for diesel exhaust or, much more importantiy, for alternative application areas.

(a) Discussion with Robert J. Goldstick, Energy Design Service, 0jai, California, December 6, 1983.

(b) Telephone discussion with Ken Johnson, Biphase Energy Systems, Santa Monica, California.

(c) Telephone discussion with B. Thielbar, DOE-Idaho, Idaho Falls, Idaho. 


\subsubsection{Thermal Storage}

A system for thermal storage that was based on the principles of gas/ liquid/solid direct contact heat transfer was tested. Actually, a slurry comprised of salt and water serves as one medium while cold air is the other medium. Because the salt serves as the main heat storage/transfer component, and because the salt is primarily in the liquid state when it enters the heat exchanger, the system is included for discussion here under the heading of gas/liquid direct contact heat exchanging.

The system just described has been used before for thermal energy storage in a low-temperature range. (a) Developed by Garrett Energy Research, the system was predicated on the assumption that if a pumpable saltwater slurry could be developed, then heat transfer could be accomplished without the need for indirect heat exchanging between the salt thermal storage medium and the water (the intermediate heat transfer fluid).

In the design, the hot slurry is introduced into a spray tower at the top and flows down, countercurrent to upflowing cold gases. As heat is transferred from the slurry to the gas strear, the salt solidifies. Consequently, the solids-to-liquid ratio of the slurry increases. Normally, this action would present a problem because pumping would be almost impossible. But research into the use of crystal habit modifiers resulted in crystal shapes and sizes that permitted easy pumping in the Garrett design. (a) This principle of crystal habit modification could be used in other applications where thermal storage is required and direct contact between the thermal storage medium and the heating or cooling fluid is desirable.

\subsubsection{Solar}

A detailed study was undertaken to assess the feasibility and potential merits of using a DCHE in connection with a high-temperature integrated thermal energy storage system for solar thermal applications (Bruckner and Hertzberg 1982a). The technology is described below.

(a) Discussion with Robert J. Goldstick, Energy Design Service, Ojai, California, December $6,1983$. 
The heat transfer and storage medium is a glassy slag. Beads of slag are melted by direct contact heat exchange in the solar centrai receiver. The molten slag is stored at $1650^{\circ} \mathrm{K}$ in an insulated storage vessel. Sensible heat is extracted from the molten slag in a DCHE spray tower in which the slag is sprayed through a high-pressure, counter-flowing working gas. The hot gas at $1500^{\circ} \mathrm{K}$ operates a $43 \%$ regenerative Brayton gas turbine. The solidified slag droplets at $985^{\circ} \mathrm{K}$ are returned to the central receiver to repeat the cycle (Bruckner and Hertzberg 1982a).

The scope of the work centered on 1) investigation of the thermophysical and chemical properties of candidate thermal energy storage media and containment vessel materials, 2) analysis of heating and melting of the storage medium in the solar central receiver, 3) study of storage medium handiing and transport, 4) development of a droplet heat exchanger model, 5) design of the thermal storage subsystem, and 6) comparison of costs.

Specific conclusions reached by the researchers suggest that although the cost of the slag storage medium is very low in comparison with other storage media, the overall storage system based on molten slag is more costly than other thermal storage technologies. However, because the system can store and utilize heat at a much higher temperature than any other storage concept, it can result in higher efficiency, in smaller power conversion apparatus and smaller heat rejection apparatus for a fixed power output, and in a reduction in the size of the solar receiver and heliostat field. These benefits may offer substantial cost savings compared to the cost of the storage system alone. Alternatively, the high temperatures made possible by this system are particularly well suited for applications to high-temperature process heating and fuels/chemicals production. These applications require high temperatures that are beyond what current thermal storage technologies can provide and they represent large potential markets (Bruckner and Hertzburg 1982a). (a)

(a) Telephone discussion with A. Bruckner, University of Washington, Seattie, Washington. 


\subsubsection{Other}

Development of suitable heat exchanger technology represents one of the most technologically challenging problems in the design of space prime power systems. In space power systems the dissipation of waste heat is critical to maintaining delicate temperature balances within the space environment. Conventional heat transfer devices are temperature-limited by materials considerations and are highly susceptible to single point failure, such as might be brought about by micro-meteorites (Bruckner and Hertzberg 1982b) or other more normal causes of single point failure. Tradeoffs are generally required between heat exchanger efficiencies and long-term reliability (Bruckner and Hertzberg 1982b).

Studies conducted at the University of Washington indicate that classical limitations posed by conventional heat exchangers can be overcome by adapting direct contact technology for space power system applications (Bruckner and Hertzberg 1982b). In the method proposed by the University of Washington researchers, convective heat transfer would occur between a low-vapor-pressure liquid metal and an inert working gas. The liquid droplet heat exchanger was examined for both heat addition to and heat rejection from a Brayton cycle.

A system such as the one just described offers many advantages over a conventional heat exchanger for space applications. First, the large heat transfer area provided by the multitude of droplets permits high heat exchanger effectiveness (0.9--0.95) in a very compact, lightweight geometry. Second, temperature limitations of conventional heat exchangers could be overcome and direct contact units could be operated at much higher temperatures. Third, pressure losses would be greatly reduced. And finally, the structural geometry diminishes chances of single point failure significantly beyond that of conventional heat exchangers.

While no systems are in operation at present, the researchers at University of Washington believe that liquid droplet DCHEs for thermal management in space can be developed using available technology. They further believe, however, that considerable work is required on a variety of technical problems to develop a practical operating device. Specific areas requiring investigation include the design details of the gas and liquid manifolds and droplet 
injector, materials compatibility problems, the details of secondary flows in the two-phase vortex, the design and testing of liquid film skimmers, and effective means to collect the spent droplets. These and other problems are currently being addressed in a program of theoretical and experimental research on the liquid droplet heat exchanger at the University of Washington.

\subsection{GAS/SOLID}

Gas/solid OCHEs have seen significant application in industrial waste heat recovery. Most of the gas/solid concepts for waste heat recovery are countercurrent devices analogous to gas/liquid spray tower heat exchangers. One device, however, uses a moving fluidized bed that moves perpendicular to the gas stream. These exchangers can be used for preheat of process materials, heat recovery from solids in calcination processes, or even for gas-to-gas heat transfer with the solids acting as an intermediate heat transport medium.

Thermal storage is another area where gas/solid systems have been applied. As with the liquid/solid thermal storage concepts, energy is stored by melting a suitable heat storage medium. In this case, however, the heat transfer fluid is a gas rather than a liquid. The gas flow can be an industrial waste heat stream or a solar Brayton cycle working fluid.

\subsubsection{Industrial Waste Heat Recovery}

Three different gas/solid waste heat recovery concepts have been identified that are all essentially countercurrent devices, that is, the flow of the dispersed solid is counter to the flow of the gas. There are considerable differences, however, in the specific methods by which heat transfer is accomplished.

A concept developed by researchers at the Compiegne University of Technology in France and the University of Western Ontario in Canada uses packing in the heat exchange column to increase the residence time of solid particles, thus allowing higher efficiencies (Large et al. 1981). This system, known as a "raining packed-bed exchanger," has been tested in a pilot-scale plant. In a 1.5-meter-diameter column with 1 meter of $25 \mathrm{~mm}$ packing, temperature gradients of $700^{\circ} \mathrm{C}$ and pressure droos of only a few millibars have been obtained with 
sand as the solid component and gas at $900^{\circ} \mathrm{C}$. Hydrodynamic stability during operation is a major concern. The need to operate at gas flows near the terminal velocity of the particles to maximize performance causes problems with backmixing and column inhomogeneity.

Recovery of industrial waste heat by dropping particles down existing exhaust chimneys is an idea being pursued at the University of Aston in Birmingham, England (Sagoo 1981 and 1982). The heated particles from this "Falling Cloud Heat Exchanger" drop into a shallow fluidized bed where their heat is recovered by immersed coolant lines. The coolant can be either water or air. The cooled particles are conveyed back to the top of the chimney by means of bucket elevator. The heat recovery particles are either steel or alumina. Overall thermal efficiencies of 55\% have been obtained in a pilotscale test facility. The problems encountered with this device have to do with distribution of both the solid particles and the gas stream, and with the durability of the particles. The gas inlet at a right angle to the chimney causes poor distribution of flow in that region. This poor distribution increases as gas flow and temperature increase. The particles tend to collect in the low velocity region, agglomerate, and then rapidly fall to the bottom due to their increased terminal velocity. The net effect is a reduction of efficiency with increasing airflow and temperature. The heat recovery ability of the unit is limited by the difficulty in achieving proper particle dispersion at high solids flow limits. Finally, problems with corrosion, erosion, and therma? shock of the particles are encountered, thus degrading their effectiveness in collecting heat. Pilot-scale tests of this concept have been performed. Currently, a full commerciai-scale assessment of the device is under way.

The "vibro-fluidized" heat exchanger is a concept that is being developed at Virginia Polytechnic Institute under sponsorship of the ECUT Program of DOE. (a,b) In this device, the solid particles are dropped down an inclined duct and intermittently bounced up into the gas stream by the conbined action of duct vibration and weirs placed on the bottom surface. Low pressure drops

\footnotetext{
(a) Telephone discussion with Y. A. LIU, Virginia Polytechnic Institute, Blacksburg, Virgnia.

(b) Telephone discussion with B. Thielbar, DOE-Idaho, Idaho Falls, Idaho.
} 
and high heat transfer rates are an advantage of this design. The device is still largely in the conceptual stage and a two-year effort at VPI is under way that will result in a pilot-scale demonstration.

Preheat of glass batch by glass furnace exhaust gases is performed by a system developed and tested by Thermo Electron Corporation of Waltham, Massachusetts (Cole and Sakhuja 1983). (a) Exhaust gases from a melter are introduced into a plenum and flow through a distributor plate, fluidizing the glass batch. The glass batch is fed into one end of the bed by a rotary airlock and heated batch is removed at the other end by an overflow weir. The preheated batch is then directed to the furnace. The exhaust gases enter at a typical temperature of $1000^{\circ} \mathrm{F}$ and leave at $700^{\circ} \mathrm{F}$. In the process, the batch is heated to $900^{\circ} \mathrm{F}$. Entrained particles are separated from the gas outflow by a cyclone and remixed with the preheated batch. A major concern is integration of the system with current melters that are designed for cold batch. Fouling of the distributor plate by the dirty exhaust gases is another problen. An automatic water spray system, triggered by excessive drop in distributor pressure, seems effective in handling the latter problem. The concept has been tested in a laboratory unit and a small field unit at a production glass plant. A pilot plant with a capacity of 4 tons/day is in the planning stages. Interest in the system by the glass industry is high. (a)

A research area receiving some recent attention is the possible use of molten salts to recover waste heat in the temperature range of $450^{\circ}$ to $1000^{\circ} \mathrm{F}$. Specifically, an idea under investigation at the University of Washington centers on using liquid carbonate salts to recover heat in the $900^{\circ}$ to $1200^{\circ} \mathrm{K}$ range.(b) According to A. P. Bruckner, the liquid carbonates should not decompose much under the harsh conditions of a flue gas environment. However, more research and development is needed to test this hypothesis.

(a) Telephone discussion with W. E. Cole, Thermo Electron Corp., Waltham, Massachusetts.

(b) Telephone discussion with A. P. Bruckner, University of Washington, Seattle, Washington. 
Additionally, one information source has indicated that a particular manufacturer is also working to develop a molten salt system that could be used to recover waste heat from industrial exhaust gases. (a) Particular applications that might benefit from such a system are glass-and metal-treating furnaces. Here, the exhaust gases are very corrosive and dirty, often containing metal salts that form slag upon cooling. This virtually eliminates indirect contact exchangers from consideration. (a) However, more information regarding the status of research and development was not readily available.

\subsubsection{Thermal Storage}

Researchers at the Institute of Gas Technology are investigating a gas/ solid high-temperature thermal storage concept under DOE sponsorship (Petri, Ong and Claar 1983). Porous sintered ceramic shapes contain a liquid thermal storage salt using surface tension forces. Salt volume fractions of $65 \%$ in the ceramic storage medium have been obtained. The ceramic support structures consist of pressed and sintered magnesium oxide powder with a mixture of sodium carbonate and barium carbonate salts as the heat storage medium. Phase change takes place at $710^{\circ} \mathrm{C}$. The rigidity of the ceramic support structure allows manufacturing in any desirable geometry and arrangement in packed-bed or orderly checker-work configurations. Proper behavior and stability of the medium is necessary for success of the concept. The ceramic support material must be able to withstand a high-temperature liquid carbonate environment. The heat storage medium must be chemically stable with respect to the gas stream, and have a low vapor pressure to minimize material losses. Performance of the concept in an engineering-scale test unit with $25 \mathrm{~kg}$ of ceramic/ salt pellets has been good. Present concerns revolve around the structure's ability to withstand thermal cycling and shock, and the mechanical behavior (creep rates and compressive loadings) in representative stacking configurations under operating conditions. Research is currently being undertaken to optimize the ceramic support structure, i.e., maximize the salt volume fraction, and provide greater volumetric heat storage capacity.

(a) Discussion with Robert J. Goldstick, Energy Design Service, Ojai, California, December 6, 1983. 
.

,

. 


\subsection{STATE OF TECHNOLOGY ASSESSMENT - FOREIGN PERSPECTIVE}

The primary mission of this study is to provide insight into domestic R\&D needs in the field of direct contact heat exchanging. However, because of the level of activity and interest exhibited by European and other foreign countries in this area, PNL researchers decided that it would be beneficial to include a perspective of foreign operating experience and research efforts. A comprehensive study of foreign experience was not possible within the scope of this project, although the potential merits of such a study are documented in the literature (Semler, Hansen and Richlen 1981). Rather, the intent of this section is to provide some moderate insight into the current state of technology development of OCHEs abroad, as well as insight into several innovative technologies that could potentially penetrate the U.S. market.

Probably the most widespread application of DCHEs, both domestically and abroad, is in the recovery of waste heat from (industrial) exhaust gas. The most common recovery system employs water as the medium to directiy contact exhaust gas, recovering both sensible and latent heat. These gas/liquid (dispersed) systems are often termed "condensing units" because the exhaust gas can actually be cooled below its dew point without causing the fouling and corrosion normally associated with acid condensation on heat transfer surfaces. Hot water produced from this type of system can be used in a variety of applications within the plant, either directly or in conjunction with coriventional heat exchangers. Further details on this type of system can be found in Section 4.4.1. Also, a study sponsored by GRI covers the domestic and international perspective of this specific DCHE application in great detail (Goldstick and KVB, Inc. 1981).

While this type of direct contact unit has only recently gained acceptance in the United States, it has been widely used in Europe for over 10 years. Currently there are about 200 units installed in the U.S. In contrast, there are approximateiy 3000 units installed and operating in Europe (Mullin 1983). This discrepancy owes to the long history of higher fuel costs with which European industry has had to contend. As a consequence of these high fuel costs, there has been economic incentive to increase fuel efficiency, and 
European interest in energy conservation activities, including direct contact heat exchangers, has been stronger for many years. A list of many of the major foreign and domestic suppliers of direct contact condensation waste heat recovery devices is contained below in Table 5.1 .

The European experience ranges from very small units $(500,000 \mathrm{Btu} / \mathrm{hr})$ used in direct contact combustion heating of swimming pools, to large (500 million Btu/hr) units used in conjunction with black liquor recovery boilers in the pulp and paper industry. The latter have also provided emission control. Within this range, virtually every type of industrial and commercial application has been installed.(a)

One interesting observation of the European experience with DCHEs is that a good rapport generally exists between the companies manufacturing the equipment and potential users.(a) oftentimes written agreements are not required. If the product fails to perform at advertised standards, the consumer is subject to minimum financial risk. Most European companies that manufacture DCHE equipment do so as a sideline to their main businesses; they have often conducted business with potential DCHE customers in connection with other equipment needs and have gained their trust through prior positive interactions. Also, the logistics are often favorable for these well-established working relationships. All of these factors contribute to the ease with which DCHE technology has penetrated the European market. By comparison, many potential U.S. users of DCHE equipment view with some skepticism manufacturer's claims reported efficiencies and are slow to initiate purchase and installation agreements. (a) This apprehension on the part of potential technology users results in lower than possible levels of market penetration. The technology is technically sound and widely applicable, but the prevailing philosophy among customers is one of skepticism.

Although a relatively new development, Hitachi Limited's oil-fluorocarbon DCHE could have application in many sectors of industry where waste gases in the temperature range of $400^{\circ}$ to $750^{\circ} \mathrm{F}$ are available. (b) The system is

(a) Discussion with Robert J. Goldstick, Energy Design Service, 0jai, California, December 6, 1983.

(b) Telephone discussion with S. Sakaguchi, Hitachi Limited, Ibaraki, Japan. 
TABLE 5.1. List of Manufacturers Surveyed by GRI

\begin{tabular}{|c|c|c|c|c|c|}
\hline No. & Name & Location & $\begin{array}{l}\text { Type of } \\
\text { Equipment (a) } \\
\end{array}$ & $\begin{array}{l}\text { Total Company } \\
\text { Sales Volume, } \\
\text { S Million/Yr }\end{array}$ & $\begin{array}{l}\text { No, of } \\
\text { Units } \\
\text { Sold } \\
\end{array}$ \\
\hline 1. & Fröling (including GGG) & Germany & $\begin{array}{l}\text { DCCHR, } \\
\text { ICHR, DCC } \\
\text { DCC }\end{array}$ & 25 & 600 \\
\hline 2. & $\begin{array}{l}\text { Industrial de Chauffage } \\
\text { (IC) }\end{array}$ & France & DCCHR & 70 & 100 \\
\hline 3. & $\begin{array}{l}\text { Aerophysics Co. (licensee } \\
\text { of IC) }\end{array}$ & U.S. & DCCHR & 0.5 & 1 \\
\hline 4. & $\begin{array}{l}\text { Spur Engineering (1icensee } \\
\text { of IC) }\end{array}$ & Engl and & DCCHR & 2 & 17 \\
\hline 5. & Heat Extractor Corp. & U.S. & DCCHR & 25 & $100-120$ \\
\hline 6. & Bayless Kenton & England & DCCHR & 10 & 12 \\
\hline 7. & A.0. Smith & U.S. & DCCHR, DCC & 500 & 2 \\
\hline 8. & Flakkt Industrial & Sweden & DCCHR & 600 & 50 \\
\hline 9. & $\mathrm{CHX}$ & U.S. & ICCHR & & 3 \\
\hline 10. & Air Frolich AG & Switzerland & ICCHR & & 100 \\
\hline 11. & Fagersta $A B$ & Sweden & ICCHR & 480 & 1 \\
\hline 12. & Hanrez S.A. & Belgium & DCCHR, DCC & 12.5 & 400 \\
\hline 13. & Sargi Burner & France & DCC & 4 & 4 \\
\hline 14. & Tomco Equi pment & U.S. & DCC & 8 & $400(b)$ \\
\hline 15. & Trane Therma I & IJ.S. & $\mathrm{DCC}$ & 658 & \\
\hline 16. & Sumi tomo & U.S. & $\mathrm{DCC}$ & 3008 & 20 \\
\hline 17. & Deltherm & France & $\mathrm{DCC}$ & & 1 \\
\hline 18. & Maxon Corporation & U.S. & $D C C$ & & 10 \\
\hline 19. & John Zink & U.S. & DCC & & \\
\hline 20. & Selas Corporation & U.S. & $\mathrm{DCC}$ & 64 & \\
\hline 21. & John Thurley & Engl and & $D C C$ & -- & \\
\hline
\end{tabular}

\footnotetext{
(a) DCCHR = direct contact condensation heat recovery, $I C C M R$ = indirect contact condensation heat recovery, DDC $=$ di rect contact combustion

(b) Not designed or applied primarily for its heating efficiency $\left(\mathrm{CO}_{2}\right.$ generation, $\mathrm{pH}$ control)
} 
described in Section 4.1 .1 of this report. The unique feature of this heat recovery system is that it permits effective coupling of a waste heat recovery system with the efficient electricity generating capabilities of an organic Rankine cycle. Steam cycles at this temperature range are not nearly as efficient. As pointed out in Section 4.1.1, the system is currently being tested in a cement plant in Japan. (a) The only analogous system under development in the U.S. would be the Biphase turbine, which also uses a working fluid to recover waste heat and to produce electricity or mechanical power. However, a suitable working fluid for direct contact use with the Biphase turbine was not identified and the temperature range of interest was somewhat lower than the Hitachi system.

One technology application area that has received mich foreign attention but relatively little domestic attention is desalination. Theoretical and appication-oriented research has been conducted in variety of foreign countries for many years. The result is a multitude of different technologies for effective desalination of seawater. Although the U.S. has not generally possessed the incentive to commit large resources on a national level, research conducted in the U.S. for geothermal applications is believed to be relevant.

Although direct contact condensers are not addressed directly by this study, it is worth noting that in many countries, the deciining opportunity to use water as the ultimate heat sink in process or energy plants has provided new incentive to use direct contact condensers with secondary heat rejection from the coolant/condensate stream to air through a conventional air-cooled heat exchanger. The current main interest is the Heller-cycle power plant, and the most effort has been in Hungary. (b) This "closed cycle" approach may gain importance in the U.S. as a greater competition arises for existing water resources.

Other more detailed descriptions of foreign involvement in the development of direct contact heat exchangers can be found in Chapter 4.0 of this report.

(a) Telephone discussion with S. Sakaguchi, Hitachi Limited, Ibaraki, Japan.

(b) Telephone discussion with K. J. Bell, Oklahoma State University, based on a lecture abstract for the International Centre Seminar on Advancements in Heat Exchange (1981). 
The consensus of opinion is that with few exceptions (and these are based primarily on the desirability of a particular end-use application), the level of understanding of direct contact heat transfer in the U.S. is in most ways comparable to European counterparts. There seems to be a great diversity of applications studied in the U.S., many in connection with alternative energy production schemes. Some of these, such as OTEC, were not even mentioned in this study because the particular DCHE design fell outside the study definition.

It does appear that the Europeans have a superior edge in applying the technology in several important areas. The practical experience gained froin extensive application (e.g., condensation waste heat recovery) to a variety of industrial and commercial end-users is a marked benefit. This benefit enables European manufacturers to enhance designs and improve levels of understanding with regard to engineering of this specific DCHE equipment more rapidly than

\section{U.S. manufacturers.}

Nevertheless, it seems that research diversification in the U.S. may be enhancing levels of innovation. For instance, the use of molten salts as a heat exchange medium was first tested in the context of high-temperature solar technology applications. It has just recently been proposed as a possible high-temperature medium to be used in direct contact heat exchanging for industrial waste heat recovery. In other words, the long-term payback of research conducted in the alternative energy areas (i.e., geothermal and solar) is now being realized indirectly. Test data and models developed for these scenarios can be (and are being) applied to develop alternative applications of these technologies. Yet, the reader should not be led by this statement to underestimate the level of innovation exhibited by European and other foreign researchers and manufacturers. A case in point is the Hitachi system mentioned earlier. 



\subsection{RESEARCH AND DEVELOPMENT NEEDS}

Research and development needs identified in this study were determined from a variety of sources. Treatment of R\&D needs in the technical literature provided a point of departure. Later discussions with authors and other research and industry experts provided further resolution to R\&D needs and priorities based on perceived technological and institutional barriers. Finally, both study contributors and other evaluators reviewed these findings as a final check of the results.

Chapter 6.0 is divided into two sections, Identification of R\&D Needs (Section 6.1) and Evaluation of R\&D Needs (Section 6.2). In Section 6.1, R\&D needs are identified and fully described. The R\&D needs are also classified according to whether they are oriented towards generic, phase combination, or application categories of R\&D needs. In Section 6.2, the R\&D needs identified in Section 6.1 are evaluated with regard to their research priority and the expected duration of the research.

\subsection{IDENTIF ICATION OF R\&D NEEDS}

The numbering system employed in this section can be described as follows: R\&D needs that fall under Section 6.1.1 (Generic R\&D) are identified with the letter "G" followed by a sequential number. The letter represents the first letter in the word "generic." Similarly, items from Section 6.1 .2 are identified with the letter "P" because the section is entitled Phase Combination Oriented R\&D. And finally, items in Section 6.1.3 (Application Oriented R\&D) are identified by the letter "A" followed by a number in sequence.

\section{1 .1 Generic R\&D}

G.1. Existing experimental and operating data need to be collected and incorporated into a data base for purposes of technology transfer. This data base can be used to improve the current understanding of process phenomenon, thus resuiting in improved modeling and predictive capabilities. Where possible, the data base should include data that characterize the following elements; DCHE equipment; fluid or solid streams; operating conditions (inciuding fiow rates and 
inlet and outlet temperatures); mass transfer; hydrodynamics of the system, particularly with regard to inlet and outlet zones; and other relevant information.

G.2. Experiments should be undertaken to fill data voids that might be identified as a consequence of developing the data base suggested in item G.1 above. General areas of concern already identified include considerations of chemical stability between various media in different process environments, and heat, mass, and momentum interaction between various media.

G.3. Basic research to enhance existing models or to develop new models that simulate DCHE performance and processes should be undertaken. Particularly weak are models for predicting 1) droplet size distribution for liquid/liquid systems, 2) heat transfer performance and two-phase flow behavior of multidroplet gas/liquid systems, 3) bubble collapse, hydrodynamics, and heat transfer characteristics of liquid/gas systems, 4) the effects of backmixing and turbulence on heat transfer and mass transfer with regard to various DCHE equipment and designs, 5) heat transfer during solidification and melting of media used in thermal storage systems, and 6) mass transfer phenomenon for low-energy scrubbing. Gas/solid systems suffer from many of the same process modeling R\&D needs as gas/liquid DCHE systems.

G.4. Effort should be expended to improve methods of selecting suitable media based on predicted compatibility, miscibility, and desired operational attributes for a specific application. Selection considerations should address whether or not mass transfer is desirable and, if it is, to what extent. At some point in the near future, it is hoped that designers will be able to design a system, including media selection, for specific applications based on available data and comprehensive theoretical models. Significant improvements in efficiency may be possible through this approach rather than through modification of some "standard" system for a particular application. 
G.5. Basic research is required to improve the level of understanding and actual methods for introducing and withdrawing media from DCHE systems. While systems of different phase combination have different specific needs, the general intent is to improve designs so that backmixing is minimized and heat transfer and media distribution are maximized. Mass transfer may also be an important factor depending on the intent of the system (i.e., scrubbing DCHE systems).

G.6. Further work is required to improve "scale-up" analytic capabilities for extrapolating performance and operational characteristics of laboratory units to industrial-sized units.

G.7. Brainstorming efforts should be encouraged that might identify innovative applications for the various DCHE types. Following these efforts, feasibility studies should be undertaken with some assessment of possible system economics, energy savings, and development problems that need to be addressed. For example, it has been suggested that bubble-up systems (1iquid/gas) may have strong potential to effect heat transfer while providing improved control of mass transfer. Yet this system approach has received very little attention and is still poorly understood.

G.8. Efforts to secure operating data from foreign sources could significantly expand the data base of information available for domestic use. These data could be incorporated into the structured data base suggested in item G.1.

\subsubsection{Phase-Combination-Oriented R\&D}

\section{Liquid/Liquid}

P.1. Methods should be studied to prevent or limit backmixing in spray columns with smail $\mathrm{H} / \mathrm{D}$ ratios.

P.2. Research is needed to improve methods for forming droplets from working fluids at high flow rates. New distributor designs should be a focal point of research. 
P.3. Investigation into the selection of working fluids that possess good thermal and system characteristics but that do not present the expense and environmental problems of freons and the operational and safety problems of the light hydrocarbons is desirable.

P.4. Some investigations should be made into the technical and practical advantages/limitations of developing and applying low-energy centrifugal force DCHEs.

Liquid/Solid

P.5. Research into identifying compatible heat transfer/storage medium combinations that best suit desired operating conditions should continue.

Liquid/Gas

P.6. Although somewhat a generic R\&D need, a study to determine in what instances mass transfer may or may not be desirable, based on application processing requirements and/or emissions requirements, could have particular significance for this relatively obscure technology. Primarily, the study would help identify potential market areas where "bubble-up" direct contact heat exchangers may offer particular advantages.

P.7. Some application testing of this technology seems warranted to determine performance characteristics and to focus R\&D needs from an application viewpoint. Specifically, mass transfer versus heat transfer rates need to be determined from testing in various applications.

Gas/Liquid

P.8. Research efforts should be directed towards identifying and testing alternate working fluids in a variety of applications and environments. For instance, identification of chemically stable working fluids for operation at higher temperatures than are currently possible with existing working fluids is one area for investigation. 
Studies to determine both the mass transfer and degradation properties of the working fluid under high-temperature conditions are similarly important.

P.g. Basic research seems warranted to gain a fuller understanding of the effects that undesirable evaporation of working fluid (droplets) has on heat transfer efficiency. An example is the negative impact on efficiencies created by evaporation of the organic working fluid that was tested in conjunction with the Biphase turbine.

P.10. Experimental research in droplet injector technology should be furthered. Specifically, studies to mitigate materials incompatibility problems at high temperatures (i.e., $1800^{\circ} \mathrm{K}$ ) should be initiated with a view to improving injector reliability under conditions pressing the state-of -the-art technology. Also, research in injector technology aimed at achieving uniform droplet size should be continued.

\section{Gas/Solid}

P.11. Research is needed in the areas of column design and media dispersion systems to prevent system performance degradation by multidimensional flow effects and particle agglomeration.

P.12. Studies should be undertaken to identify particle materials that have adequate thermal and heat transport properties that can also resist erosion, corrosion, and thermal cycling.

P.13. Some attention should be focused on the selection and testing of suitable salts that could be used in a molten salt DCHE concept. Specifically, determination of salt behavior in a typical industrial exhaust gas would be a likely starting place. Data from solar concepts are applicable to some extent.

\subsubsection{Application-Oriented R\&D}

The R\&D needs are classified according to the four areas of application that this study has treated: 1) industrial waste heat recovery, 2) thermal storage, 3) solar and 4) geotherma 1. 
Industrial Waste Heat Recovery Applications

A.1. Condensation Units - systems analyses, Second Law thermodynamic analyses and, in some cases, feasibility studies are needed to determine compatibility between sources (i.e., applications) of hot water, and potential uses of this low-temperature energy source. Specific areas of interest not currently addressed by industry but with vast potential include: 1) district heating and all of the associated contractual/legal ramifications of such systems;

2) electric conversion using heat engines operating in the $160^{\circ}$ to $180^{\circ} \mathrm{F}$ temperature range, and the possible use and development of the Nitinol engine; 3 ) diversification of companies to produce other products (i.e., agriculture) on-site that could benefit from the large volumes of low-temperature water; and 4) possible coupling with dessicant cooling (air conditioning) systems, since such systems generally require regeneration in the $140^{\circ}$ to $160^{\circ} \mathrm{F}$ temperature range. Areas typically addressed by industry are limited to space heating, process stream preheating, and domestic hot water production.

A.2. Condensation Units - efforts should be directed towards transferring the technology to industry. Specifically, there seems to be a credibility problem in the general engineering community in accepting reported integrated boiler efficiencies approaching $95 \%$ to 98\%. Educating the public regarding the pros and cons of such systems could greatly enhance their acceptance and subsequent usage. The Association of Energy Engineers has sponsored some work in this area.

A.3. Condensation Units - effort should be expended to examine the favorable environmental consequences, on a national level, that could be made possible by widespread cleansing of industrial flue gases with this type of heat recovery equipment. Air pollution reductions could be examined in relation to minor contamination of water sources. 
A.4. Biphase Turbine - research is needed to identify, test, and match DCHE working fluids to specific application environments in support of a gas/liquid DCHE system that could be used in conjunction with the Biphase turbine.

A.5. Biphase Turbine - there is a need for research that would determine potential application areas for DCHE/Biphase turbine systems. Also, a small-scale follow-up study to determine the most promising areas of research as an outcome of the original search for a diesel application working fluid could prove beneficial.

A.6. General - identification of suitable working fluids that are compatible with operation in the $200^{\circ}$ to $500^{\circ} \mathrm{F}$ flue gas range is needed. Topics to be addressed should include, but not be limited to: stability of the working fluid and tendencies to become contaminated or to otherwise degrade; system costs; and emissions due to carryover of the working fluid into the exhaust gases. The latter is a critical limitation of many organic working fluids at present.

A.7. General - engineering of gas distribution mechanisms used in conjunction with fouling and corrosive flue gases needs to be improved to prevent or correct fouling of this equipment.

Thermal Storage Applications

A.8. Salt Systems - research into selecting and testing salts for gas/ solid systems is important, specifically, those systems that might prove suitable in dirty and corrosive waste heat streams.

A.9. Salt Systems - methods need to be developed to prevent the solidification of heat storage medium from interfering with discharge of thermal storage devices. The use of crystal habit modifiers should be examined more closely in this context. Advantages can be realized in slurry pumping and distribution.

A.10. Salt Systems - improved strategies for preventing of tank corrosion are needed, specifically, as demonstrated in the case of the "heat battery" developed by $0 E M$ and discussed in this report. Priorities should be placed on identifying "cost-effective," corrosionresistant designs. 
Geotherma 1 Applications

A.11. General - research is needed in liquid/liquid systems to prevent fouling of ancillary equipment (pumps, valves, and measurement control devices).

A.12. General - improved control strategies should be investigated for steady-state operation of liquid/liquid columns to prevent operational transients that result in system shutdown.

A.13. General - investigation should be continued into developing costeffective methods to prevent working fluid loss due to carryover. Solar Applications

A.14. Integrated Solar Storage - research should be undertaken to identify particular processes (i.e., thermochemical, etc.) that could benefit from the high temperatures made possible from the integrated high temperature solar thermal technology described in the body of this report. This study should also include some quantification of the economic and energy savings.

A.15. Integrated Solar Storage - research should be devoted towards identifying methods to reduce the system cost so that it is more competitive with alternative technologies. Specifically, lower cost storage vessel liners and pumping techniques must be identified. Other Application

A.16. Thermal Space Management - research, design, and testing of liquid film skimmers and of effective means to collect spent droplets in a zero gravity environment are needed.

\subsection{EVALUATION OF R\&D NEEDS}

R\&D needs from Section 6.1 are evaluated with regard to their research priority, and the anticipated length of time required to complete the research. Priority is rated as follows: high $(H)$, medium (M), and low (L). R\&D priorities identified within the Phase Combination Oriented and Application Oriented research categories are not meant to be compared. Rather, each priority is a 
discrete, subjective evaluation of the perceived contribution that the R\&D activity could make in furthering the state of technology understanding, efficiency, and subsequent usage in that particular application. No comparison should be drawn between R\&D activities that impact different types of applications or that are, in essence, different types of systems.

R\&D needs are also evaluated with regard to their expected duration. In other words, the R\&D needs are classified as either short term (S) or long term (L) in this section. Short-term R\&D is perceived as efforts requiring less than one to two years. Long-term R\&D is perceived as efforts requiring more than one to two years at moderate levels of effort. A summary of the evaluation of R\&D needs is contained in Table 6.1 .

Results summarized in Table 6.1 can be used in several ways. Probably the most constructive and beneficial use of these results is to suggest important areas for research to be conducted at several levels. Depending on the focus of particular research programs, this summary can provide insight into relevant R\&D needs that might accelerate commercial development and subsequent implementation; improve efficiency; increase potential market penetration; or, on a more basic level, render a design concept feasible from a technological standpoint. Both H/S (high priority/short duration) and $H / L$ (high priority/ long duration) research needs have been identified that pertain to several different levels of research and technology applications. These $H / S$ and $H / L$ R\&D needs warrant careful consideration. 
TABLE 6.1. Evaluation of R\&D Neets

R\&D Need $(a)$

Discrete
Priority $(b, c)$ Duration (d)

GERIC

G.1 Data collection and technology transfer

G.2 Experimentation to fill voids identified in data collection

G.3 Basic research to enhance models and process understanding

G.4 Methods to improve media selection

G.5 Inprove understanding and design of inlet and outlet zones

G.6 Enhance scale-up predictive capabilities

G.7 Identify new and innovative applications

G.8 Collect detailed foreign operating data

$\begin{array}{ll}H & S \\ M & L \\ M & L \\ H & L \\ H & L \\ M & L \\ H & S \\ L & S\end{array}$

PHASE COBINATION ORIENTED

Liquid/Liquid

P.1 Methods to linit badkmixing

P.2 Inprove methods for forming droplets

P.3 Improve selection of working fluids

P.4 Investigate possible use of law centrifugal force

Liquid/Solid

P.5 Identify compatible heat transfer/storage media

$\begin{array}{ll}L & L \\ H & L \\ M & L \\ H & S\end{array}$

Liquid/Gas

P.6 Study desirability of mass transfer

P.7 Detentine mass transfer versus heat transfer rates

M S

$\begin{array}{ll}M & S \\ H & S\end{array}$

Gas/Liquid

P.8 Identify and test altemate working fluids

P.9 Research into the effects of droplet evaporation

P.10 Research into droplet injector design

Gas/Solid

P.11 Studies of colum design and media dispersion

P.12 Identification of suitable particle materials

P.13 Selection of appropriate change-of-phase salts

$\begin{array}{ll}M & L \\ M & L \\ H & L\end{array}$

APPLICATION ORIENTED

Industrial haste Hat Recovery

A.1 Condensation thits - systers analyses for end uses

A.2 Condensation Units - technology transfer

A.3 Condensation thits - enviromental inpacts of usage

A.4 Biphase Turbine - identify/test suitable working fluids

A.5 Biphase Turbine - detentrine potential application areas

A.6 General - identify working fluids for 200 to $500^{\circ} \mathrm{F}$ range

A.7 General - engineering of gas distribution mechanisms

$\begin{array}{ll}H & S \\ H & S \\ H & S \\ H & L \\ M & S \\ H & L \\ L & L\end{array}$


TABLE 6.1. (contd)

RRD Red (a)

\begin{tabular}{l} 
Discrete \\
Priority $(b, c)$ \\
\hline
\end{tabular}

APPLICATION ORIENTED (contd)

Themal Storage Applications

A.8 Salt Systers - selection and testing of appropriate salts

A.9 Salt Systems - prevent interference with thenmal discharge

A.10 Salt Systers - prevent tark corrosion in "heat battery" concept

$\begin{array}{ll}H & L \\ M & L \\ H & S\end{array}$

Geothental Applications

A.11 General - prevent fauling of ancillary equipment

A.12 General - improve control strategies

A.13 General - investigate means to prevent working fluid loss

Solar Applications

A.14 Integrated Solar Storage - identify processes that cauld benefit

A.15 Integrated Solar Storage - identify methods to reduce cost

$M \quad L$

$\mathrm{H} \quad \mathrm{S}$

$\mathrm{H} \quad \mathrm{L}$

ather Applications

A.16 Themal Space Managerent - design/test droplet collection devices

H L

(a) Detailed descriptions of these R\&D neect can be faund in Section 6.1, Identification of R\&D reeds.

(b) $H=$ high, $M=$ medium, $L=10 \mathrm{w}$.

(c) Priorities are not relative within the phase conbination or application oriented categories of R\&D needs. Pather, each priority is a discrete, subjective evaluation of the contritation that the R\&D activity could make towarts improving those specific technology applications that are impacted by the identified R\&D. No comparison should be drawn between R\&O activities that impact different types of applications.

(d) $L=$ long term, $S=$ short tem. 



\subsection{REFERENCES}

Abe, Y., et al. 1983. "Charge and Discharge Characteristics of a Direct Contact Latent Thermai Energy Storage Unit Using Form-Stable High Density Polyethylene." In ASME-JSME Thermal Engineering Joint Conference Proceedings, Vol. 2, eds. Yasuo Mori and Wen-Jei Yang, pp. 365-370.

Boehm, R., et a1. 1983. "Direct Contact Heat Exchanger for Geothermal Power Plants." In 11th Intersociety Energy Conversion Engineering Conference, pp. 754-760.

Bruckner, A. P., and A. Hertzberg. 1982a. High Temperature Integrated Thermal Energy Storage System for Solar Thermal Applications. SERI/STR-231-1812, SERI, Golden, Colorado.

Bruckner, A. P., and A. Hertzberg. 1982b. "Direct Contact Droplet Heat Exchangers for Thermal Management in Space." In Proceedings of the 17th IECEC, August 8-12, 1982, Los Angeles, California, pp. 107-111.

Carlsson, B., and A. Schmidt. 1981. "Reflux Boiling Direct Contact Heat Exchanging in Heat-of-Fusion Storage Using Salt Hydrates." In 2nd World Congress on Chemical Engineering and World Chemical Exposition, October 1981.

Cole, W. E., and R. K. Sakhuja. 1983. "A Fluidized Bed Heat Exchanger to Preheat Glass Batch." Paper presented at the 2lst National Heat Transfer Conference, July 24-27, 1983, Seattle, Washington.

Culbreth, W., G. Johnson, and E. Marscha11. 1981. "Heat Transfer and Hydrodynamics During Drop Formation and Release in a Liquid--Liquid Direct Contact Heat Exchanger." In Heat Transfer--Milwaukee 1981, AIChE Symposium Series $77(208): 19-25$.

Della Vida, P. I., F. J. Franz, and R. S. Weinreich. 1980. GLEF DirectContact Heat-Exchanger Program, Final Report. DAI Technical Report POV-7902OD2-TR, Daedalean Associates, Inc.

Fulton, R. L. 1978. "Developments in 0irect Contact Heat Exchange." In Earth Sciences Division Annual Report 1978, pp. 55-57. LBL-8648, Lawrence Berkeley Laboratory, University of California, Berkeley, California.

Goldstick, R. J., and KVB, Inc. 1981. Survey of Flue Gas Condensation Heat Recovery Systems. GR I 80/0152, The Gas Research Institute, Chicago, Illinois.

Helgeson, N. L., and W. R. Studhalter. 1981. "Using the Biphase Turbine to Generate Useful Energy from Process Streams." In Proceedings of the 1981 Conference on Industrial Energy Conservation Technology, April 26-29, 1981, Houston, Texas, 2:613-623. 
Jacobs, H. R. 1977. "Evaluation and Design Considerations for Liquid-Liquid Direct Contact Heat Exchangers for Geothermal Applications." ASME paper 77 HT-2.

Jacobs, H. R., et al. 1977. "Operational Limitations of Direct Contact Boilers for Geothermal Applications." ASME paper submitted for presentation at the AIChE-ASME Heat Transfer Conference, Salt Lake City, Utah, August $15-17,1977$.

Jacobs, H. R., and R. F. Boehm. 1980. "Direct Contact Binary Cycles." Source Book on the Production of Electricity from Geothermal Energy, $P p$. 413-47l. DOE/RA/28320-2.

Knight, J. F. and J. J. Perona. 1981. "A Mass Transfer Model for a Spray Tower Direct Contact Heat Exchanger." In Heat Transfer--Milwaukee 1981 AIChE Symposium Series $77(208): 11-17$.

Kuraki, S., and P. Brothers. 1980. Direct Contact Liquid--Liquid Heat Exchanger for Solar Heated and Cooled Buildings. Prepared for the Department of Energy by the Solar Energy Applications Laboratory, Colorado State University, Fort Collins, Colorado.

Large, J. F., et al. 1981. "New Fluidized Solids Concepts for Heat Exchange Applied to Future Energy Conversion Processes." Paper presented at the Third international Conference on Future Energy Concepts.

Mines, G. L. 1982. Preliminary Report on the Baseline Thermal and Hydraulic Performance Tests of a Sieve Tray Direct Contact Heat Exchanger. EGG-GTH6101, Idaho National Engineering Laboratory, Idaho Falls, Idaho.

Mines, G. L., 0. J. Demuth, and D. J. Wiggins. 1983. Thermal and Hydraulic Performance Tests of a Sieve-Tray Direct-Contact Heat Exchanger Vaporizing Pure and Mixed Hydrocarbon Rankine Cycle Working Fluids. EGG-2253, EG\&G Idaho, Inc., Idaho Falls, Idaho.

Mullin, R. September 5, 1983. "Condensing Units Gain Users Despite Impurity Concerns." Energy User News 8(36): 1.

Nichols, K., et al. 1980. Final Design, Installation and Baseline Testing of $500 \mathrm{~kW}$ Direct Contact Pilot Plant at East Mesa. LBL-11153, Lawrence Berkeley Laboratory, University of California, Berkeley, California.

Nichols, K. E., et al. 1981. $500 \mathrm{~kW}$ DCHX Pilot Plant Evaluation Testing. LBL-13339, Lawrence Berkeley Laboratory, University of California, Berkeley, California.

Nichols, K. E. 1981. "Direct Contact Heat Exchanger Applications for Binary Cycies." In Minutes: Tenth Meeting of the Centers for the Analys is of Therma 7 Mechanical Energy Conversion Concepts, Brown University, Providence, Rhode Istand. 
Nichols, K. E., and D. R. Prigmore. 1981. "Design and Operations of a $500 \mathrm{~kW}$ Direct Contact Geothermal Pilot Plant." In Geothermal Energy, 9(8): 27-32.

Parkinson, G. 1980. "Heat Exchange: New Uses for Direct-Contact Units." Chemical Engineering, June 30, 1980, pp. 56-60.

Petri, R. J., E. T. Ong, and T. D. Claar. 1983. "High-Temperature Salt/ Ceramic Thermal Storage Phase-Change Media." In 18th Intersociety Energy Conversion Engineering Conference, Vol. 4, pp. 1769-1774.

Rao, O. N., and M. F. Mohtadi. 1983. "A Novel Direct Contact Heat Exchange System for Efficient Heating of Water." ASME/JSME Engineering Conference, March 20-24, 1983.

Sagoo, M. S. 1981. "The Development of a Falling Cloud Heat Exchanger--Air and Particle Flow and Heat Transfer." Heat Recovery Systems 1(2):133-138.

Sagoo, M. S. 1982. "The Falling Cloud Heat Exchanger Commercial Pilot Plant Operation." Heat Recovery Systems 1(2):23-30.

Semler, T. T., E. J. Hansen, and S. L. Richlen. 1981. Final Report: Potential Industrial Applications for Direct Contact Waste Heat Recuperator Systems. EGG-CS-5328, EG\&G Idaho, Inc., Idaho Falls, Idaho.

Sideman, S. and Y. Gaty. 1966. "Di rect Contact Heat Transfer with Change of Phase: Spray--Column Studies of a Three-Phrase Heat Exchanger." AIChE Journal 12(3):296-303.

Somer, T. G., et al. 1973. "Pilot Plant Study of Desalination by Direct Contact Heat Transfer." Desalination 13:221-229.

Suratt, W. B., and G. K. Hart. 1977. "Testing of Direct Contact Heat Exchangers for Geothermal Brines." ASME paper 77-HT-4.

Wiggins, D. T., G. L. Mines, and E. Wahl. 1982. "Thermal Performance of a Geofiuid Direct Contact Heat Exchanger." In Proceedings of the Seventh International Heat Transfer Conference, Volume 6, ed. U. Griguil, et a1., pp. 371-378. Hemisphere Publishing Corporation, New York.

Whitlock, J. 1981. "Raft River Pilot Binary Plant." In Minutes: Tenth Meeting of the Centers for the Analys is of Thermal/Mechanica TEnergy Conversion Concepts, Brown University, Providence, Rhode Island.

Wright, J. D. 1981. An Organic Rankine Cycle Coupled to a Solar Pond by Direct-Contact Heat Exchange--Selection of a Working Fluid. SERI/TR-6311122, Solar Energy Research Institute, Golden, Colorado.

Wright, J. D. 1982. Sizing of Direct-Contact Preheater/Boilers for Solar Pond Power Plants. SERI/TR-252-1401, SoTar Energy Research Institute, Golden, Colorado. 



\section{DISTRIBUTION}

No. of

Copies

OFFSITE

30 M. Gunn

U.S. Department of Energy

Energy Conversion and

Utilization Division

1G-080 Forrestal Building

Washington, D.C. 20585

27 DOE Technical Information Center

R. Boehm

Energy Resources Laboratory

Mechanical and Industrial

Engineering Department

University of Utah

Salt Lake City, UT 84112

J. Brogan

U.S. Department of Energy

Office of Energy Systems

Research

Washington, D.C. 20585

A. P. Bruckner

Department of Aeronautics and Astronautics FS-10

College of Engineering

University of Washington

Seattle, WA 98195

W. E. Cole

Thermo Electron Corporation

45 1st Avenue

Waltham, MA 02254

R. J. Goldstick

Energy Design Service

221 N. Alvarado Avenue

Ojai, CA 93023
No. of

Copies

\author{
H. Jacobs \\ Energy Resources Laboratory \\ Mechanical and Industrial \\ Engineering Departinent \\ University of Utah \\ Salt Lake City, UT 84112
}

S. Sakaguchi

Hitachi

Mechanical Engineering Research Laboratory

1-l Saiwai-Cho

3--Chome

Hitachi--Sni

Ibaraki--Ken 317

JAPAN

K. M. Sekins

2755 Northup Way

Bellevue, WA 98004

W. Thielbar

U.S. Departinent of Energy

Idaho Operations office

550 Second Street

Idaho Falls, ID 83401

J. D. Wright

Solar Energy Research Institute

1617 Cole Boulevard

Golden, C0 80401 
ONS ITE

DOE Richland Operations Office

H. E. Ransom

49 Pacific Northwest Laboratory

W. B. Ashton

H. J. Bomelburg

D. L. Brenchley (10)

J. E. Danko

D. E. DeBellis (5)

G. J. Hane

S. G. Hauser

R. A. Hutchinson

B. M. Johnson

R. W. Vallario (20)

Publishing Coordination MA (2)

Technical Information Files (5) 